\title{
Infant Health and Longevity: Evidence from A Historical Intervention in Sweden*
}

\author{
Sonia Bhalotra ${ }^{\dagger}$ \\ Martin Karlsson $\ddagger$ \\ Therese Nilsson ${ }^{\S}$
}

February 24, 2016

${ }^{*}$ We are grateful to Silke Anger, Atheendar Venkataramani, and participants of various conferences and seminars for their feedback on earlier versions of this paper. We also wish to thank the Swedish Foundation for Humanities and Social Sciences for financial support.

${ }^{\dagger}$ Department of Economics, University of Essex, Wivenhoe Park, Colchster CO4 3SQ, United Kingdom. Contact: srbhal@essex.ac.uk

†University of Duisburg-Essen, Schützenbahn 70, 45127 Essen, Germany. Contact: martin.karlsson@unidue.de

$\S$ Department of Economics, Lund University, Box 7082, SE-220 07 Lund, Sweden, and Research Institute of Industrial Economics (IFN), Box 55665, SE-102 15 Stockholm, Sweden. Contact: therese.nilsson@nek.lu.se 


\begin{abstract}
This paper investigates the potential of an infant intervention to improve life expectancy, contributing to emerging interest in the early life origins of chronic disease. We track individuals from birth to death, and are able to identify age and cause of death. The intervention was pioneered in Sweden in 19311933, and appears to have been pivotal in the emergence of universal infant care programmes in the Scandinavian countries during the creation of the Welfare State. It provided information and support to mothers, with an emphasis on nutrition and sanitation, while monitoring infant care through home visits and clinics. We estimate that the average duration of programme exposure in infancy led to a $1.56 \%$ point decline in the risk of infant death ( $24 \%$ of baseline risk) and a $2.56 \%$ point decline in the risk of dying by age 75 ( $7.0 \%$ of baseline risk). We directly identify intervention-led declines in the risk of dying after the age of 50, dominated by reductions in cancer and cardiovascular mortality. We find no evidence of selective utilisation, and the estimates are similar when we exploit within-mother variation in outcomes. Intervention impacts are larger for children born out of wedlock. Our findings are of contemporary relevance for richer and poorer countries.
\end{abstract}

Keywords: Infant care; Antenatal care; Infant Mortality; Life expectancy; Chronic disease; Early life interventions; Programme evaluation; Sweden.

JEL classification: I15; I18; H41. 


\section{Introduction}

This paper presents what would appear to be the first attempt to identify causal effects of a publiclyprovided infant care programme on longevity. We study a historical, pioneering intervention that was implemented in the early 1930s in response to a cessation in the decline of infant mortality in Sweden, at a time when its incidence was similar to that in many of today's poor countries (Razavi, 2012). Trained health workers provided information, support and monitoring of newborn health through home visits alongside which there was an extension of services offered through local health clinics. There was a particular emphasis on nutrition and sanitation. The programme was part of a broader international Infant Welfare Movement of the time (Fildes et al., 2013), fueled by concerns about population decline, exacerbated by the First World War (Davis, 2011), and it constituted a significant step in the development of the modern welfare state in Sweden.

Similar early childhood and home-visiting programs are increasingly being introduced in developing countries, but despite a surge in funding for these programs, there are few systematic evaluations (Engle et al. 2007). Mother-baby programs with a home-visiting component are also currently being refurbished and re-introduced in richer countries including the US and the UK, and there is a lively interest in their potential to curb early life disease risk $\left.\right|^{1}$ There is growing interest in a wider literature in the efficacy of policies delivering information and in the role of monitoring and feedback, but limited evidence of their success, or its persistence over the longer term (see below). Our first contribution is to estimate the size and distribution of impacts of a "soft intervention" on infant survival, although our larger contribution probably lies in our assessing the extent to which the programme had impacts on longevity over and above direct impacts of infant survival. We explore mechanisms by investigating cause of death in childhood and late adulthood, schooling, and outcomes for older siblings.

Historical improvements in life expectancy in rich countries stemmed from infant mortality declines at the turn of the century generating an unprecedented improvement of thirty years in the course of the twentieth century (Cutler et al. 2006). Child mortality rates continue to be unnecessarily high in poor countries, with 1 in 10 children dying before their $5^{\text {th }}$ birthday compared with 1 in 143 in richer countries. The toll in 2012 was estimated to be 6.6 million deaths, of which $74 \%$ occurred in infancy and $44 \%$ in the first month of life (Jones et al., 2003; Black et al., 2010). On the premise that morbidity scales with mortality, infant mortality is widely used as a proxy for infant health (Bozzoli et al., 2007).2

\footnotetext{
${ }^{1}$ For instance, the Maternal, Infant, and Early Childhood Home Visiting programme, created under the Affordable Care Act of 2010 in the US, provided 1.5 billion USD over 5 years in funding to expand evidence-based home visiting programs in states to serve the most vulnerable children and families. In 2007, the UK government instituted the Family Nurse Partnership, inspired by the Nurse Family Partnership in the USA.

${ }^{2}$ While HIV-AIDS and chronic disease have contributed to limiting life expectancy growth in today's poor countries since 
Recent research suggests that conditions in childhood may causally raise the risk of chronic disease in adulthood. The mechanism proposed in the biomedical literature is that infection and poor nutrition early in life may inhibit the development of vital organs or modify endocrine processes with irreversible negative effects on health at later ages. Of particular interest here is the hypothesis that infant morbidities result in the individual being programmed with metabolic traits that predict the onset or progression of chronic disease but that are latent earlier in the lifecourse (Barker, 1990, 1994; Barker and Osmond, 1986). There is some evidence, from selected and sometimes small samples, that childhood programmes benefit adult health or longevity (Campbell et al., 2014, Hoynes et al., 2012, Hjort et al., 2014; Bütikofer et al. 2015) but evidence of population-level effects on longevity and on causes of death in late adulthood remains scarce.

One reason that such estimates are scarce is that data pose a significant challenge to identifying this relationship, which involves tracking a sufficiently large number of individuals over their lifetime. To address this challenge, we purposively digitised individual birth certificate data from historical parish records for a large and representative sample of roughly a quarter of a million individuals born during 1930-34 in 114 rural parishes and 4 cities 3 We then matched births to the Swedish Death Index (cf. Fischer et al., 2013) using name and exact birth date and place (parish) of birth. We validated our match of administrative birth and death records using burial (Swedish Genealogical Society, 2012) and tax records and, in addition, we used a 1970 population register to get updated surnames for individuals (i.e. females) who got married, which made it possible to use surnames as an additional matching variable $4^{4}$ We were able to track $96 \%$ of births for a period of 75 years. Among our sample cohorts, $36.5 \%$ did not survive to the age of 75 , which makes it a good proxy for longevity. Importantly, by tracking individuals to this age, we are able to directly model impacts of the infant health intervention on chronic disease using cause of death information in the registers. The availability and analysis of such data is fairly rare (as we elaborate below).

The other, more familiar challenge is to identify causal effects of the programme. We are aided in this by three features of the programme. First, it was time-delimited, starting 1 October 1931 and ending 30 June 1933, and it was announced as such, which implies it will have limited impact on selective migration and fertility. The narrow window of eligibility for the programme also limits the possibility that the 1990s, infant mortality remains a major factor. While the direct contribution of infant mortality to longevity is wellestablished, there is limited evidence of its indirect effects, namely the extent to which infants who survive infectious disease are predisposed to chronic disease and shorter adult lives.

${ }^{3}$ National vital statistics were available in Sweden before they were available in any other European country. All newborn children in Sweden automatically became members of the Church of Sweden. Parish records were linked to other administrative data, including records of in- and out-migration, births and baptisms, bans and marriages, and deaths and burials.

${ }^{4}$ Since almost all individuals were unique based on birth date, first names and parish, this variable was in most cases only used for validation. 
programme impacts are confounded by unobserved trends. Second, it was universal, in contrast to many contemporary programs in, for instance, the US, that target low-income women and children, including the Food Stamps programme (Hoynes et al., 2012) and Head Start (Ludwig and Miller, 2005). Third, programme documentation indicates that the National Board of Health selected the seven medical districts where the trial was implemented "randomly" to be representative of the country. We nevertheless use the 1930 census to create matched controls at the parish level, and we obtain estimates from comparison of exposed and unexposed siblings within mother. Further, we investigate endogeneity in the composition of births, and the socioeconomic gradient in programme uptake exploiting unusual access to utilisation data.

Using birth parish to identify eligibility to the programme and exact birth date to compute duration of exposure, we find large and significant impacts of eligibility for the infant-care programme on the probability of the individual surviving to the ages of 1,5,40 and 75 . We estimate that a child with the average duration of potential exposure to the programme in infancy experienced a $1.56 \%$ point decline in the risk of infant death, which is $24 \%$ of baseline risk, and a $2.56 \%$ point decline in the risk of dying by the age of 75 , which is $7.0 \%$ of baseline risk. The estimates imply that the programme accounted for between 20 and 50 per cent of the actual decline in infant mortality, and was associated with reductions in mortality which persist to this day. This is a fairly remarkable achievement given that a decade of stagnation in infant mortality preceded the intervention, and that the intervention coincided with the Great Depression in Sweden. Further analysis shows that the programme significantly reduced childhood deaths assigned to pre-term birth, low birth weight and congenital malformations. These causes accounted for a third of infant and a fourth of child mortality in the pre-intervention period and the average duration of exposure led to a $1.47 \%(1.46 \%)$ point decline in infant (child) mortality. We shall discuss how this was linked to the content of the intervention.

Our analysis shows that the gains in survival are persistent until age 40, though there are no additional gains by this age. Our finding that there are gains in longevity (or survival to age 75) over and above the gain in infant survival and that these additional gains emerge after mid-life is consistent with latent effects of programme exposure on chronic disease, since the onset of chronic disease is typically after the age of 50. The biological mechanisms are not fully understood or documented, but it is argued that the early life environment may set the switch for genome expression later in life (Petronis, 2010) 5

\footnotetext{
${ }^{5}$ Our finding that the infant intervention lowered infant mortality may be seen as a "first stage" which suggests that the intervention improved infant health, even for survivors, given that health and mortality move together. So, when studying longevity and cause-specific mortality in adulthood for exposed individuals, we know that infant health was a mechanism. We do not exclude effects on long term outcomes through other pathways such as that the programme left mothers better informed and so influenced their nutritional or other choices after infancy, or that infant health improves cognitive capacity; more on this in Section 5.9 .
} 
We directly investigated chronic disease as a mechanism for enhanced longevity. Conditional upon survival to age 50, we find that exposed individuals are $2.7 \%$ points less likely to die before the age of 75 . The absolute reductions in all-cause mortality are similar for men and women but the proportional gains are larger for women and the cause-specific survival gains are consistently different by sex. Investigating cause-specific mortality rates, we find that the largest reductions are in deaths from cancer (women) and cardiovascular causes (men), though we also find programme led reductions in deaths from infections.

We add to a small body of evidence that cardiovascular risk is a function of early life conditions (Hjort et al. 2014; Bütikofer et al., 2015; Van den Berg and Modin, 2013), including breastfeeding (Horta and Victora, 2013) and nutrition (Kinra et al., 2008), which were components of the programme we study. There appears to be less evidence for (colorectal) cancer, so we explored the source of this result further: Medical experts at the time of the intervention highlighted the elevated prevalence of digestive disorders in the population we study and their association with poor nutrition (Hellström et al., 1934). Moreover, medical evidence shows that breast-feeding, clean water and a diet including fibre, fresh fruits and vegetables all contribute to reducing the risk of gastrointestinal infection and inflammation (Kumar et al., 2015; Rinne et al., 2005), and these were key components of the infant programme that we analyse. While cardiovascular mortality rates have declined considerably since 1970, cancer mortality rates have not (Bailar and Gornik, 1997), so while further research is merited to confirm our findings, we make a potentially important contribution in identifying the origins of cancer risk as lying partly in modifiable elements of infant health. We identify much larger impacts on cancer-mortality of exposure to the infant health programme than Bailey and Goodman-Bacon (2015) find from adult exposure to community health centres introduced in the United States from the mid-1960s.

Mother fixed effects estimates are not significantly different from estimates obtained on the same sample using pooled data. Using digitised records of programme uptake and number of visits for a (representative) sub-sample of districts, we find little evidence of selection into the programme. We find some evidence consistent with the hypothesis that parental investments favour treated children and thereby reinforce public investment, inasmuch as older siblings of treated children do worse than matched controls. We check and confirm that our results are not confounded by potentially correlated geographical and time variation in availability of other public services including hospital delivery and education, which seems particularly relevant in a context where the welfare state was expanding on many margins at the same time. We use pre-intervention data to construct matched controls for each parish (or city) and are able to test for a match on outcomes. We additionally test for and reject differential pre-trends between treated and control in infant survival outcomes. We also test that the treated districts were 
indeed representative of the country.

The programme contributed to narrowing health inequality. For instance, children born to single mothers experienced a reduction in infant mortality of as much as $6.9 \%$ points and a reduction in the chances of dying by age 75 of $11.44 \%$ points. They constituted $12 \%$ of all births at the time (Statistics Sweden, 1940). While the programme was universally available in treated areas, programme documents highlighted the importance of reaching this group (Steenhoff, 1931), so these results provide a crude consistency check on identification of programme effects.

Since the programme coincided with the Depression, we used tax records to generate an indicator of the severity of the financial crisis at the parish level and to study heterogeneity in impact by this variable, but found no significant differences.

We consistently control for coverage by a programme providing antenatal care services in the treated districts and find no direct effects of this programme. This result resonates with the conclusions from recent surveys which show limited impacts of antenatal interventions on infant mortality (or birth weight and pre-term birth) (Currie and Rossin-Slater, 2015; Fiscella, 1995; Hollowell et al., 2009; Gresham et al., 2014).

This paper contributes to a number of streams of the literature. First, it contributes to a literature on the power of information (Dupas, 2011) and monitoring and feedback (Andrabi et al., 2013; Bandiera et al. 2009) to effect behavioural change. We provide some of the first evidence of large infant survival gains from an information and monitoring programme and also the first evidence of long term longevity effects of such a programme. The second is a thriving literature evaluating the effects of early life health shocks (or interventions) on education and labour market outcomes and on morbidities among survivors (Almond, 2006; Bhalotra and Venkataramani, 2011; Almond et al., 2011; Bharadwaj et al., 2014; Andreella et al., 2015), to which we contribute by estimating impacts on longevity.

Emerging in parallel with our work are two other studies which analyse similar interventions that were implemented in Denmark and Norway a few years after the intervention considered here (Hjort et al., 2014, Bütikofer et al., 2015). There are differences between the historical programs, and differences in data availability between the countries, as well as differences in the questions we pose, as a result of which the three studies complement each other in several respects. Bütikofer et al. (2015) show that mother and child services provided by philanthropic institutions had positive effects on education and earnings and on indicators of metabolic syndrome at age 40, and Hjort et al. (2014), who evaluate a public home visiting programme find that treated individuals are less likely to die in middle age, in particular of cardio-vascular causes at age 45-57. 
Our substantive contribution relative to these studies is that we have assimilated data that allow us to estimate effects of our programme over the life course, from birth to death. This offers three advantages. First, we are able to analyse longevity or, effectively, survival to more advanced ages. Second, by virtue of tracking individuals until age 75 , we capture the time of the lifecycle when chronic disease risk is significant. We provide estimates for a wider range of causes of death than previous studies and, in particular, we provide the first results for cancer mortality. Third, our estimates for longevity are not conditional on the individual having survived to a certain age. Survival selection may be quantitatively important for the 1930s cohorts since infant mortality rates in Scandinavia were of the order of 6\%, and our data show that $10.5 \%$ of our sample cohorts had died by the age of 40 . Moreover, as mortality rates in childhood and mid-life will tend to vary by sex and by the socioeconomic status of parents, survival selection will also generate compositional effects.

We start by establishing a strong "first stage", showing impacts of the intervention on infant health (for which infant survival is a marker) and, unlike the Norway and Denmark studies or indeed other related studies (Hoynes et al., 2012; Aizer et al., 2014) that examine food stamps and cash transfers, we examine cause-specific mortality in childhood ${ }^{6}$ We then show that additional health gains are latent, emerging after the age of 50. The related studies of Hjort et al. (2014); Bütikofer et al. (2015) and Hoynes et al. (2012) are unable to study health conditions later in life because of data constraints and this makes it hard for them to model mortality from chronic disease 7

Our study also differs from existing studies in methodological terms. First, the aforementioned studies are of programmes that were rolled out over a long period of time and although the authors condition upon municipality-specific trends, the long period introduces potential concerns about endogenous fertility or migration, or the play of other interventions 8 In contrast, the Swedish programme we study was initiated and concluded in less than two years. Second, in Denmark and Norway, adoption of the programme at the municipality level is potentially endogenous whereas our Swedish programme was implemented all at once in seven districts by Federal dictate. The treated areas were chosen by the Government

\footnotetext{
${ }^{6}$ In a study that focuses on infant mortality rather than long run effects of the Danish home-visiting programme, Wüst (2012) looks at death causes at an aggregate level. She finds that infant deaths on account of acute enteritis declined, consistent with the nurses' promotion of breastfeeding and good infant nutrition.

${ }^{7}$ In Hoynes et al. (2012), the oldest individuals in the sample are age 53 and the only statistically significant impact of childhood exposure to food stamps is on obesity.

${ }^{8}$ The Danish programme was rolled out between 1937 and 1974, though the authors analyse a restricted period of early rollout, 1937-1949, during which 350 of 1345 municipalities adopted it. It was centrally designed but locally implemented and municipalities decided when to initiate the programme, so this decision was potentially correlated with municipality characteristics and the adoption of other programs. The Norwegian programme is similarly evaluated for a restricted period of the rollout, 1936-1955. Similar to the Danish programme, it was locally implemented, but by philanthropic institutions rather than the state and the content of the programme varied across municipalities. Sweden also implemented a nationwide rollout of a mother-baby programme starting in 1937 and achieving nationwide coverage in the 1950s. The trial that we analyse here preceded the nationwide Scandinavian programs and would appear to have been inspired their wider adoption - see the next section.
} 
to be representative of the country (Kungl. Propositioner, 1930). Third, we have access to sibling data and household background characteristics that allow us control for mother-level unobserved heterogeneity, to assess parental investment responses, and to evaluate heterogeneity in programme effects. Fourth, we have access to utilisation data which enable us to assess whether treatment effect heterogeneity is due to differences in utilisation or differences in treatability. Further discussion of related studies is in the Results section.

The costs of a "war against infant mortality" are orders of magnitude smaller than the costs of a "war against chronic diseases". And the potential benefits are large: Murphy and Topel (2006) estimate that the cumulative gains in life expectancy after 1900 were worth over USD 1.2 million to the representative American in 2000. Chronic disease accounted for 68\% (38 million) of all global deaths in 2012 and is on the rise. It exerts a major burden on individual wellbeing and work capacity, on state health expenditure, and on families' ability to invest in the younger generation $9^{9}$ Policies targeting chronic diseases tend to focus upon treatment or else on modifying adult behaviours to mitigate risks. But there is enormous unexplored potential to address the origins of chronic disease in infancy 10 .

\section{Infant Health and the Emergence of the Intervention}

Infant mortality had started to decline in all Western countries by the turn of the 20th century (Loudon, 2000). Sweden experienced an impressive decline from above $10 \%$ in 1900 to $6.5 \%$ in 1917 (Corsini and Viazzo, 1997; Andreella et al., 2015). However, as is clear in Figure 1, from 1920 to 1930, there were no further substantive declines, and a similar stagnation was noted elsewhere, for instance, in Denmark and the USA (Moehling and Thomasson, 2014, Wüst, 2012), 11 The deterioration of public health in the 1920s, coupled with falling birth rates (Wisselgren, 2005), gave rise to an intense public debate in Sweden on how to improve conditions for expectant mothers and newborns. The public concern in Sweden was part of an international phenomenon known as the Infant Welfare Movement (Fildes et al. 2013), fuelled by concerns about population decline, exacerbated by the First World War (Davis, 2011).

\footnotetext{
${ }^{9}$ In the USA today, average healthcare costs for individuals with a chronic condition are five times greater than for those without, chronic diseases account for $75 \%$ of healthcare spending, and for 7 of 10 deaths; see http://www. forahealthieramerica.com/ds/impact-of-chronic-disease.html

${ }^{i 0}$ This is relevant for today's rich and poor countries alike. Infant mortality rates in the 1930s in Sweden were similar to the rates in many of today's poor countries, and the causes of death were similar. A major difference between then and now is that there has been considerable medical innovation since the 1930s (e.g. the introduction of antibiotics, much more knowledge about diet and behaviours like smoking). However a majority of poor households in poor countries do not have access to the relevant knowledge and technologies. Life expectancy is estimated to be as low as 38 years in Sierra Leone, between 50 and 55 years in several African countries, and between 80 and 85 years in most OECD countries, the average gap between rich and poor countries being about thirty years (WHO, 2012).

${ }^{11}$ The leading infant death causes in 1930 was illness and weakness of newborn, and respiratory and infectious disease.
} 
The rising concern about public health led, in 1929, to a Royal Commission being charged with the task of modernising maternal and neonatal care and it proposed the intervention that we analyse. In December 1930, the programme was approved by the National Board of Health (Medicinalstyrelsen) and the final proposal was accepted in the Swedish Parliament on 29 May 1931. The programme started on 1 October 1931 and ended 30 June 1933, after a decision to extend it was taken in the summer of 1932. The state committed SEK 30,000 (USD 133,000 in current prices) to funding the intervention. With the intention to mirror the whole of Sweden, seven health districts were selected to receive free and extended antenatal and infant care services for the delimited trial period ${ }^{12}$

At the time some services were already being provided in most Western countries, but these tended to be local or private initiatives in larger cities, often targeting certain groups. For instance, although the UK Maternal and Child Welfare Act in 1918 required local authorities to provide antenatal care clinics, there was considerable fragmentation in maternity services across the the UK until the start of World War II when it became routine practice to visit every newborn in the UK at home (Chamberlain, 2006, Loudon, 2000). Home visiting programmes were available in the USA in 1920-1929. In Sweden, before the programme was initiated in 1931, there were two types of institutions for infant and family care at scattered locations. One relied mainly on visits to physicians and the distribution of cow milk powder to poor mothers (Mjölkdroppen) and the other involved home visits by nurses to families across the socioeconomic status distribution but mostly in larger cities (Barnavårdscentralsystemet; cf. Wallgren, 1936; Stenhammar et al. 2001). An important feature of the intervention we analyse is that, in the selected districts, it provided universal care.

\subsection{Organisation of the Activities}

The trial intervention of 1931-1933 was monitored by the National Board of Health but implementation was decentralised to the district level, adapted to heterogeneous local conditions, and led by physicians. In order to ensure uniform standards, an educational event was organised in the capital Stockholm in July 1931, during which staff from all participating districts attended lectures and courses for five days, in which the objectives of the project were detailed and staff visited existing health clinics. Particular emphasis was placed on the importance of providing care on equal conditions to all mothers.

In each test district, a health centre for infant care with regular office hours was started ${ }^{13}$ and in all locations there were intense outreach activities to inform people about the available services. Historical

\footnotetext{
${ }^{12}$ The participating districts were Lidköping, Hälsingborg, Harad, Råneå, Jokkmokk, Pajala and Mörtfors. These districts. included 57 parishes and two cities.

${ }^{13}$ In the more remote areas, advice was also given by telephone and urine samples sent by mail.
} 
documents indicate that there were recurrent announcements concerning the availability and opening hours of the health centres in local newspapers, on public pinboards, and in churches in the test districts (Lindsjö, 1934). Figure D.9 provides an example from the local newspaper in the district of Hälsingborg.

The project focused on preventive care and involved three main types of activities, all provided free of charge, which were guidance services and examinations at the surgeries, home visits, and information campaigns. Children were weighed and monitored at the clinics, and sickness was diagnosed early, with children being referred to doctors as needed. Mothers were given guidance and encouragement to breastfeed and provided with illustrated advice on when and how to give the child proper nutrition at various stages of development, and how to monitor newborn health (see e.g. Swedish Red Cross, 1928 ; Ernberg, 1930). Nutritional advice for all children included recommendation of cod-liver oil and fruit juice rich in vitamin $\mathrm{C}$, and a blutsaft rich in iron for premature children. For children transitioning to solid foods, cereal, fresh fruit and vegetables were recommended as part of a balanced diet. Figure D.10 shows an extract from a leaflet given to all enrollees. A focal point in the public debate was the situation of single mothers and children born out of wedlock, who had significantly worse health prospects than the rest of the population (Steenhoff, 1931).

Home visits were seen as an important part of the project (Lindsjö, 1934). Visits were made by nurses and aimed at ensuring that families followed the recommendations on infant and child care given by physicians, but also at acquiring knowledge of the household's environment and circumstances. At the time many families lived in cramped conditions, sanitary standards were poor and pests, such as lice, mange and rats were rife; see (Nordström, 1938). Advice was given on hygiene, sanitation and cleanliness in the household. Interventions of this sort are likely to be more cost-effective than diseasespecific interventions as, by educating and supporting mothers' preventive behaviours and investments, they tend to generate externalities.

The individual forms which were completed by the programme nurses are not all archived, but the few sample forms which still are left also carry some important information about the emphasis of the intervention. For each participating infant the nurse record contains: name, date of birth, marital status and cohabitation of the parents, and birth order. In addition, the form contains a 'family anamnesis', birth weight, feeding status, and the state of the family dwelling. The family anamnesis part was rarely completed, but whenever it was, it typically contained information on the parents' tuberculosis status. Feeding status was almost always recorded, and in the overwhelming majority of cases, breastfeeding was reported - the alternatives being mixed feeding or formula feeding from a bottle. Information on the dwelling typically concerns whether adequate space was available in the home. 


\subsection{Utilisation and Evaluation}

Programme eligibility was determined by birth date: all children less than one year of age were eligible at the beginning of the programme, and all children born during the trial became eligible (see Figure 2). Participating doctors and nurses were obliged to keep records of their activities using the abovementioned standard forms for each mother and child, and to keep a detailed log of the utilisation of services at the individual level. We were able to acquire and digitise these logs for four of the seven participating districts (they appear to have been destroyed for the others). These data indicate that, on average, there were 2.8 visits to clinics and mothers received 3.9 home calls per enrolled child and that, in all, around 2,600 children were enrolled in the programme, which represents a large proportion of eligible families in the chosen locations (see Table C.11, 14

Despite some initial scepticism, ${ }^{15}$ auditing reports suggest that the intervention induced behavioural changes amongst participating families leading to improvements in diet and hygiene (Steenhoff, 1934). Participating physicians attributed substantial improvements in child and maternal health to the intervention, which motivated the roll-out of a similar scheme all across the country from 1937 and the passage of a bill in the national parliament legislating free maternal and infant care with equal access for all. The field trial may hence be seen as a seed of an emerging welfare state. It seems likely that the trial also influenced the decision to rollout similar programs in Norway in 1936 and in Denmark in 1937 (Moehling and Thomasson, 2014; Wüst, 2012; Hjort et al., 2014; Bütikofer et al., 2015).

\section{Data Sources and Matching Procedure}

\subsection{Matching Procedure}

Administrative documents describing the introduction of the programme underline that the intervention districts were chosen to reflect the diversity in local conditions with respect to inter alia, population density, demographic structure, and living standards (Kungl. Propositioner, 1930). Importantly, infant mortality was given no consideration in the selection of participating districts. We nevertheless generate matched controls at the parish level. The seven medical districts assigned to participate in the intervention comprised two cities and 57 rural parishes. We matched these to two cities and 57 rural parishes which were not exposed to the intervention, and these control locations belonged to 38 different medical

\footnotetext{
${ }^{14}$ See Figure 6 for a histogram of utilisation.

${ }^{15}$ There was scepticism at the national level - in 1914 two motions for better care of childbearing women and their newborns and for the establishment of maternity care facilities had been rejected in the National Parliament.
} 
districts.

The matching was done using a range of observable parish characteristics drawn from the 1930 census. The best matches (denoted $\mathcal{J}_{M}(i)$ ) were identified using the Mahalanobis distance metriq ${ }^{16}$, defined as

$$
\mathcal{J}_{M}(i)=\arg \min _{j} \sqrt{\left(X_{i}-X_{j}\right)^{\prime} S^{-1}\left(X_{i}-X_{j}\right)}
$$

where $X_{i}$ is the vector of observable characteristics for a parish belonging to a test district, namely, average income, net wealth, employment shares in manufacturing and agriculture, population density, proportion of fertile married women, and a dummy variable for urban locations, and $S$ denotes the covariance matrix of the vector of observable characteristics. The matching was done in random order and without replacement. In our regression analysis (cf. Section 4 below), observations from the control group were weighted based on their population size relative to the population size of the treated locations they were matched to. Thus, each control observation matched to parish $c$ is weighted according to $w_{\mathcal{J}_{M}(c)}=\sqrt{N_{c} / N_{\mathcal{J}_{M}(c)}}$ where $N_{c}\left(N_{\mathcal{J}_{M}(c)}\right)$ denotes the 1930 population size in the test (control) district. This ensures covariance balance for the variables used in the matching procedure. The reduction in bias comes at the cost of reduced efficiency of estimates. However, the reduction in efficiency is likely to be small since half of the observations (the treated group) have weights equal to one and 90 per cent of individuals have weights within the range $(0.46,1.98)$. Robustness checks showed that the results are insensitive to the weighting scheme used (results available upon request). Below, we assess match quality by conducting tests of differences in means for a set of observable covariates, discussed below. Figure D.11 shows a map of the treated and matched-controls districts ${ }^{17}$

\subsection{Data Sources}

The data are purpose-built using myriad sources. We digitised individual level data from administrative records maintained by the historical parish for the 57 parishes and two cities in the seven trial districts and for the 59 areas that they were matched to for the years 1930-1934. The sample contains 24,710 deliveries

\footnotetext{
${ }^{16}$ King et al. (2011) compare the effectiveness of alternative matching estimators for causal inference. They argue that the commonly used propensity score matching estimator often approximates random matching but that, contrary to conventional wisdom, random matching is not benign i.e. it can degrade inferences relative to not matching at all. They show that the Mahalanobis metric does not have this problem. Also Frölich et al. (2015) and Zhao (2004) show that Mahalanobis distance dominates propensity score matching in many contexts.

${ }^{17}$ The administrative unit used for the map is the parish which is a lower level than the medical district. For example, in the Norrbotten region, there were four test districts containing seven parishes in total.
} 
resulting in 24,374 live births 18 The parish records contain exact date of birth, whether stillbirth or live birth, child sex, mothers' age and marital status, and parents' occupation (which we transform into professional classes based on the HISCO classification; cf. Leeuwen et al., 2002). The parish records also include subsequent mortality by cause for mothers and infants covering all deaths for the period up until 1946. A very detailed and strict reporting procedure regarding death causes was introduced in 1911, which improved reporting from rural areas. Local clergymen had to make monthly reports to Statistics Sweden on the likely cause of death of persons in cases where no doctor had been involved. These notes and reports were then reviewed and confirmed by a GP who reported the final cause of death to the bureau $\sqrt{19}$ The records thus allow us to track mortality by cause during the first 10-15 years of life for the sample individuals born between 1930-34.

To identify mortality beyond this, and to validate information on mortality during childhood, we used the Swedish Death Index (cf. Fischer et al., 2013) which includes the universe of all deaths occurring between 1901-2009. We also collect information on whether a child was born in a hospital from hospital birth records 20

Individual records were matched based on date of birth, sex, forename, surname, and birth parish. To validate the matching, we use a dataset containing burial records (Swedish Genealogical Society, 2012). As a second source of validation of adult mortality we used tax records from the 2002-2013 period. Most individuals can be uniquely matched based on first name, date of birth, and parish of birth. We used a 1970 census to get additional information on surnames, which is pertinent for women as they traditionally changed their surnames upon marriage. Surnames were used to validate the match, and in the rare cases of duplicates, to identify the correct match. Whenever we found conflicting information between data sources, for example, when we found individuals recorded as earning an income after being deceased, we checked the records manually. Thus, the mortality information in our dataset is very

\footnotetext{
${ }^{18}$ In the $17^{\text {th }}$ century, the Swedish clergy created an information system that included all individuals in their parishes older than 6 to 7 years. By the mid- $18^{\text {th }}$ century, this registration included the entire population. The information system was based on the annual catechetical examination of every household, where the clergy examined knowledge of the catechism as well as the reading ability of all household members. The Office of the Registrar General (Tabellverkskommissionen), founded in 1749, compiled national statistics from the ecclesiastical registry (Högberg, 2004). Membership of the Church of Sweden could actively be cancelled if an individual wanted to enter another denomination, but church records nevertheless covered all citizens.

${ }^{19}$ For details on the reporting of deaths, cf. Karlsson et al. (2014); Statistics Sweden (1915); Hyrenius (1914) and Hultkvist (1940).

${ }^{20} \mathrm{At}$ the time a clear majority of births were home births with a midwife: in 1930, only 24 per cent of births were institutional deliveries. However, an increasing proportion of births took place in hospitals (Statens Offentliga Utredningar. 1945). In parallel to parish records of births, each hospital birth was recorded in a hospital record - so that hospital births were recorded twice. We digitised all hospital birth records in all regions containing parishes included in our data. Births in hospitals outside these regions were identified based on discrepancies between official and actual parish of birth: until 1947, the population registers included the parish of delivery instead of the home parish of the parents, whereas our parish records include the home parish. Thus, a comparison between the parish record and register data reveals hospital births. In the few cases where such a discrepancy between official birth parish and home parish was identified, we checked manually that the child was actually born in hospital.
} 
carefully assimilated and checked. We investigated emigration and we find that our sample cohorts were very unlikely to migrate, for example, only a handful of individuals migrated during the first ten years of life (evident in the parish data), and these individuals were dropped from the dataset. Table C.13 presents summary statistics, and Appendix A provides variable definitions.

Of all births in the sample cohorts, 1930-34, we identify a certain death date for 9,793, and we note that 16,217 were recorded as having an income in 2002 tax records, 7 individuals emigrated before 1950 according to the parish records, and 1,002 individuals had no death date and no tax records but we assume that they are still alive (note that an individual can have a known death date and an income reported in 2002). The death register also contains deaths occurring outside Sweden - while the information is particularly reliable for the Nordic countries, there are also entries from Germany and North America and, in total, $2-3 \%$ of recorded deaths in the relevant cohorts occurred abroad. We checked that our results are robust to dropping emigrants from the analysis.

We link the individual records in our data to two additional sources, which provide further information on later-life outcomes. For all individuals who died in Sweden from 1952 onwards, we imported the death cause based on the official death cause register (The National Board of Health and Welfare, 2012). These death causes are combined in groups based on the ICD classification and the number of deaths in each individual category. In addition, we collected the immatriculation books of all secondary schools that were active in Sweden around 1940. Roughly 20 per cent of each cohort left the basic schooling track to take on secondary schooling, which led to an increase in total years of schooling by at least two years (Fischer et al., 2016).

We created another dataset at the district level using annual reports of each of the 447 medical districts of Sweden (provinsialläkardistrikt). District physicians provided yearly summary statistics on deliveries, the number of midwives, child mortality, delivery complications and maternal mortality, amongst other variables, based on the local midwives' standardised diaries. We collect this information for the years 1930-1934; see Table C.12 for summary statistics. Two additional variables were collected at the parish level: information on the year a parish switched from 6 to 7 years of compulsory schooling, and on the year of extension of the school year (from 34.6 to 36.6 to 39 weeks) ${ }^{21}$ This information was transformed into two variables: a continuous variable corresponding to the total number of weeks of schooling from year 1 to year 6 for each parish/cohort combination, and a dummy variable taking on the value one if a cohort in a certain parish was exposed to the compulsory schooling extension. Children who moved

\footnotetext{
${ }^{21}$ At the time of the intervention compulsory schooling was six years, but school districts could provide seven years of mandatory schooling and in 1936 the Government decided that seven-year schooling should become compulsory. The reform was implemented during twelve years and thus not implemented in all districts at the same time. The reform on extensions of weeks of instructions was implemented in a similar way. See Fischer et al. (2016) for more detailed information on the reforms. 
away from their parish of birth were treated as having been exposed to the reform status applying in their parish of birth.

We recovered utilisation data from archived physician and nurse records from four districts and matched them to individual birth records. This source is less detailed than the individual forms mentioned above, but it includes a complete list of each enrolled child's utilisation. These lists cover about half of the eligible sample of women and children and, as is clear from Table C.14, summary statistics for this subsample are similar to those for the overall for all available relevant characteristics. We use these data below to investigate gradients in uptake by indicators of socio-economic position, and to gauge impacts of treatment on the treated.

\section{Empirical Strategy}

We identify programme impacts by interacting birth-date based eligibility with being born in a treated parish or city, conditioning on cohort and location fixed effects. All children aged 0-12 months during the programme period 1 October 1931 to 30 June 1933 in a treated area were eligible but for different durations, so our estimation method is a difference-in-differences (DID) approach with varying treatment intensity.

In the main empirical analysis, we contrast three different specifications, which differ in the control variables included. In a first specification, we include only the regressors strictly required for the DID analysis:

$$
y_{i c j}=\alpha+\beta T_{c}+\gamma D_{j}+\delta D_{j} T_{c}+\kappa_{c}+\epsilon_{i c j}
$$

where $y_{i c j}$ is a survival outcome of child $i$ born on date $c$ in parish $j, T_{c}$ is the duration in months of eligibility for a child born on day $c$ (including theoretical eligibility of children born in non-treated parishes), $D_{j}$ is the treatment status of parish $j$ (equal to one if the parish is treated) and $\kappa_{c}$ are fixed effects for quarter of birth times year of birth. The parameter $\delta$ estimates the intent-to-treat (ITT) effect, which is the effect, for each additional month of eligibility, of making the services available. This estimate is the relevant parameter for cost-benefit analysis when policy makers are unable or unwilling to make utilisation of services mandatory.

Under the assumption of no selection into treatment, equation (2) may consistently estimate the 
effect of programme exposure. The fact that the locations and timing of the intervention were set by national authorities with the explicit aim of representativeness, suggests that this assumption may well be true. However, the composition of births in treated and control areas may change over time for reasons related or unrelated to the intervention, or there may be regional variation over time arising from other interventions that correlates both with the programme and the outcomes we analyse. These factors could invalidate the raw DID estimates (cf. Ziebarth and Karlsson, 2014; Lechner et al., 2015). For this reason, we considered a range of richer specifications:

$$
y_{i c j}=\alpha+\beta T_{c}+\gamma_{j}+\tau_{j} c+\delta D_{j} T_{c}+\lambda X_{i}+\kappa_{c}+\epsilon_{i c j}
$$

We now include parish fixed effects $\left(\gamma_{j}\right)$ and parish-specific linear trends $\left(\tau_{j} c\right)$. We allow individual heterogeneity to be absorbed by covariates $X_{i}$ that include the sex of the child, an indicator for whether it is a singleton or multiple birth, the marital status of the mother at birth and dummies capturing old ( $>32.3)$ and young $(<25.8)$ mothers, with mothers in the middle age category constituting the omitted case, and indicators for the occupational class of the father. We also include individual indicators of hospital birth status and exposure to each of two compulsory schooling reforms ${ }^{22}$

A comparison of estimates based on equations (2) and (3) may be thought of as an evaluation of the validity of the matching algorithm: if it has picked a suitable control group, further control variables should not be needed, and the estimated effects should be the same in different specifications (cf. Oster, 2014). In addition, the estimates of the richer specification in equation (3) will deliver unbiased estimates of the treatment effect if either the matching algorithm or the regression adjustment is correctly specified (these are thus doubly robust in the sense of Imbens and Wooldridge, 2009) and for this reason, it is our preferred specification.

In Section 5.4.2 below, we shall further report tests of pre-trends, an event study analysis, an analysis of fake interventions in the period following our study, and a randomisation exercise in which we repeatedly assign a placebo treatment within each parish pair. For a discussion of randomisation inference in DID designs, see Abadie et al. (2012); Karlsson and Pichler (2015).

To allow for time-invariant unobserved heterogeneity at the mother level which may determine selection into programme uptake or fertility, we consider a third specification including mother fixed effects (cf. Bhalotra, 2010; Van den Berg and Modin, 2013). This is a substantial advantage but it comes at the cost of using a smaller sample, which is that of women with at least two births in the sample pe-

\footnotetext{
${ }^{22}$ The schooling reforms will of course not have an impact on infant and child mortality - in these regressions they are simply placebos - but for adult survival, they are potential confounders.
} 
riod. As this is likely to be a selected sample, we report estimates on it with and without mother fixed effects so that we can isolate changes in coefficients created by controlling for mother-level unobserved heterogeneity from changes created by sampling this group of women.

In Section 5.4.3, we analyse programme anticipation effects on fertility. We investigate whether birth rates, birth characteristics and other welfare reforms are correlated with the programme of interest, similar to conducting a test of balance (Pischke and Schwandt, 2014). We also investigate whether programme impacts persisted beyond the duration of the programme. This is of substantive interest and, also, of statistical interest as it would imply contamination of the control group comprising children born after the intervention who had no direct exposure to it.

At the same time as the infant intervention that we study, the Government trialled an intervention for pregnant women. Women who were at any stage of pregnancy between October 1931 and June 1933 were provided with improved antenatal care services. Therefore, some of the infants treated by the infant intervention were treated in the fetal period by the antenatal intervention and it is important that we take account of its effects. The raw correlation of duration of eligibility for the antenatal and the postnatal interventions is 0.32 and, conditional on eligibility for any one intervention, this falls to 0.13. Still, in every specification we consistently control for duration of antenatal programme eligibility of the mother of the index child.

In Section 5.5, we estimate heterogeneity in programme impact by population sub-groups including boys vs. girls, out-of-wedlock births and births to younger mothers. We allow for differences in long run survival impacts by indicators of the individual child being exposed to other, potentially complementary reforms, which are hospitalisation of birth, lengthening of the school year, and extension of primary schooling by a year. We also examine differences in impact by parish characteristics, namely, a proxy for disease conditions in the mother's birth year and a proxy for the severity of the financial crisis (the Great Depression).

The main estimates are intent-to-treat estimates using all births in the sample areas. For the subsample for which we have data on uptake and utilisation, we estimate impacts of utilisation, instrumenting this with programme exposure. Under the assumption that the duration of eligibility (which depends only on birth date) is orthogonal to unobservable differences in the health of children (conditional upon birth quarter and birth year), these 2SLS estimates identify the treatment effect on participating children (ATT).

We also estimate programme impacts on siblings to assess whether the reform may have induced parents to reinforce investments in index children at the expense of unexposed children. We investigate 
mechanisms for long run effects on longevity by analysing cause-specific mortality and higher education.

\section{Results}

We now present the survival estimates, followed by a discussion of potential threats to identification, and an investigation of heterogeneity in programme impact and potential mechanisms.

\subsection{Infant Survival}

Table 1 presents impacts of duration of potential exposure to the intervention on survival to ages $1,5,40$ and 75. The odd-numbered columns present estimates from a parsimonious specification in which the controls are the main effects (an indicator for treated region and dummies for quarter $\times$ year of birth) and the duration of exposure to the antenatal care programme. In the even-numbered columns we introduce parish fixed effects, parish-specific linear trends and the covariates listed in the preceding section.

Here we discuss estimates from the richer specifications. The intervention is estimated to have reduced infant mortality by $1.56 \%$ points for individuals with the average duration of exposure conditional upon non-zero exposure, which is $24 \%$ of the mean of the pre-intervention infant mortality rate. The addition of controls enlarges the coefficient but the change is not significant, which raises our confidence that the treatment indicator is picking up exogenous variation in programme eligibility rather than unobserved heterogeneity in treated parishes or differential pre-trends between treated and control parishes. The coefficient on the infant programme exposure variables is similarly invariant to dropping the control for the antenatal care programme. A similar intervention in Denmark is estimated to have led to a smaller reduction in infant mortality of $0.5-0.8$ percentage points, possibly because it focused upon urban areas, which may have had a better health infrastructure prior to the intervention (Wüst, 2012).

A study of underprivileged mothers in the USA shows that they systematically under-estimate the extent to which they can influence child development (Cunha et al., 2013), which suggests the scope for programs such as ours that combine information and salience to improve child outcomes. In general information trials show mixed results, see Dupas (2011), but a recent study which randomized information on nutrition and diet to mothers in Malawi shows significant improvements in child nutrition (Fitzsimons et al. 2014). This is relevant given that an important component of the Swedish intervention we analyse was provision of information on nutrition and breastfeeding to mothers. We discuss the evidence for this as a mechanism in Section 5.9.2 below.

The antenatal care intervention has no direct impact on infant survival: the coefficient is small and 
imprecisely determined. These findings are consistent with the evidence surveyed in Currie and RossinSlater (2015) who show that infant care programs including home visiting programs in the US have clearer long run benefits than prenatal programs. Reviews of the biomedical evidence similarly suggest that infant mortality and pre-term birth, low birth weight and neonatal mortality, are in general not significantly responsive to antenatal care interventions, not even when they are targeted at the socially disadvantaged and vulnerable women for whom potential impacts are largest (Fiscella, 1995; Hollowell et al., 2009; Gresham et al., 2014). Antenatal programs often include advice and assistance for delivery that reduce complications at birth and this is one mechanism by which they are expected to reduce infant (and maternal) mortality. However Sweden introduced a major expansion of midwife provision starting a century before the intervention we analyse (see Pettersson-Lidbom, 2014). So, another explanation for why we find no impacts of the antenatal care intervention is that much of the information provided to expectant mothers was already available prior to the $1930 \mathrm{~s}{ }^{23}$

\subsection{Longevity}

We modelled longer range survival rates of the sample cohorts to assess whether, among individuals who survived infancy, those who were exposed to the infant programme lived longer. We analysed survival to ages 5,40 , and 75 . We chose age 5 because the hazard of mortality tends to be highest at birth when individuals have limited immunity and to then decline exponentially to age 5 , after which it flattens noticeably. We chose age 40 as an age by which maternal mortality risk has been realized, and we chose age 75 as this was a "ripe old age" to achieve for the 1930s cohorts in our sample, $36.5 \%$ of whom were dead by this age. We model survival to ages 5, 40 and 75 conditional upon birth rather than conditional upon survival to age 1 because survival to age 1 is endogenous. Also when introducing mother fixed effects, we would have to condition upon all children of a mother in the sample having survived to age 1.

We find significant effects of programme exposure duration on survival to each of the chosen age thresholds (see Table 1). The coefficients on survival to ages 5 and 40 are very similar to the coefficients for survival to age 1 which suggests persistence of the survival advantage accruing to cohorts exposed to the programme in infancy, but no additional survival advantage to those who survived infancy, up until age 40. It is of some interest given that a growing body of experimental evidence finds that programme

\footnotetext{
${ }^{23}$ Sweden was a forerunner in obstetric care, and had professionalized birth assistance in the early 18th century, achieving a maternal mortality rate in 1900 that was half that in England and Wales and less than half that in the United States (Högberg. 2004). Also, we investigated our utilisation data for both programs and found that, while utilisation of the infant programme was high and occurred across the SES distribution, uptake of the antenatal programme was lower, more varied across regions and on average skewed in favour of married women and women of higher socioeconomic status, possibly because of the social stigma associated with illegitimate pregnancies, and the greater weight of single mothers among low-SES women. This will also have limited any effects of the antenatal care intervention.
} 
impacts fade. For example, the Perry and Abecederian preschool demonstrations, the Head Start programme and Project STAR in the US show fade out of test score gains (see Almond and Currie, 2011a, for a review). The importance of follow up is therefore increasingly recognized. In our context, it is conceivable that effects will have faded because of relapse of treated behaviours or because of endogenous behavioural responses that neutralise the effects of the intervention ${ }^{24}$ However our results suggest that health gains in infancy persist, consistent with infancy being a critical stage of development and with dynamic complementarity across stages of development. It is also consistent with programme-driven learning within mothers that persists over time.

There is however a substantial rise in the coefficient associated with survival to age 75 (from -0.20 to -0.33 ), an increase of $65 \%$, which suggests that individuals who survive infancy carry an advantage from exposure to the infant-intervention that makes them hardier late in life. For eligible children with the mean duration of exposure, the programme is associated with a $2.56 \%$ point reduction in the probability of dying by the age of 75 , which relative to the mean of $36.5 \%$ is a $7.0 \%$ reduction in the risk. The increase in the coefficient is substantial, and the pattern of results suggests that post-infant survival gains from the intervention are concentrated in late adulthood (after age 40), consistent with the onset of chronic disease being later in life. To confirm this, we conditioned on survival to age 50 and found that treated individuals had a significant $2.7 \%$ greater chance of surviving to age 75 than control individuals (see Section 5.9.2 below). As for infant survival, also for survival into adulthood, we find no discernible impacts of the antenatal care intervention.

The only other study that attempts to model changes in longevity flowing from a change in public policy is Aizer et al. (2014), who study a cash transfer programme directed at single mothers in early $20^{\text {th }}$ century America 25 They find that cash transfers to poor families in early twentieth century America improved the probability of male survival past the age of 70 by $10-20 \%$, and the probability of survival past age 80 by $9-15 \%$. However ours was a universal programme and since the cash transfer programme in America was targeted at poor families and especially single mothers, the relevant comparison is with births out of wedlock in our sample. Below we show that our infant intervention raised the chances of survival to the age of 75 by $18.8 \%$ of baseline probability for this group. Fischer et al. (2013) find that an extension of compulsory schooling by one year reduced the risk of mortality between school leaving age and age 70 by about 2.5 percentage points which is $7 \%$ of the baseline risk. Andreella et al. (2015) find

\footnotetext{
${ }^{24}$ For example it may have been that infant survival improved because of intensive monitoring, feedback and home-visiting, but that when this ceased upon the child reaching the age of twelve months, the mother reverted to "old habits" pertaining to nutrition and health so that, by the age of five, the exposed birth cohorts showed smaller gains in survival rates than the control-group.

${ }^{25}$ Matching births to death records was much harder in their data.
} 
that a one standard deviation improvement in the mother's disease environment in infancy (as measured by the local IMR) reduces mortality risk between ages $50-70$ by 0.7 percentage points, which is $4 \%$ of the baseline risk. We discuss studies that link early childhood to chronic disease in Section 5.9.2 where we present our estimates for chronic disease.

\subsection{Within Mother Estimates}

We introduce mother fixed effects to control for any selection on time-invariant mother-level traits, such as for instance time preference, altruism towards children or ability. This restricts the sample to mothers with at least two births which is about half of the full sample, so we also present pooled estimates on this subsample, see panel B Table 1 . The coefficients estimated on the pooled sample are larger than in panel $\mathrm{A}$, and the only difference is that they are on the subsample. This is consistent with mothers who have closely spaced births (and hence two within the period 1930-34) being negatively selected (see Table C.14), it being well established that births preceded by a short interval suffer higher infant mortality risks (Bhalotra and Soest, 2008). Thus larger programme impacts amongst these women probably arise from their children being more "treatable". Importantly, the fixed effects estimates in panel C, identified from variation in programme exposure among siblings, are consistently larger than the pooled estimates. However, the differences in the coefficients between panels B and C are not significant, suggesting no significant selection.

\subsection{Threats to Identification}

In this section we discuss tests of matching, common pre-programme trends, and behavioural responses to the programme that may be correlated with the survival outcomes.

\subsubsection{Match Quality}

For each of the parishes in the trial, the nearest neighbour in terms of observable characteristics was identified. Panel A of Table 2 presents summary statistics for observable characteristics from the 1930 census on which the matching was done. We show the standardised difference ('Std. Dif.') (Imbens and Wooldridge, 2009) between the treatment group and the matched controls (labelled "matched"). Panel B of the table compares treated and matched-control areas on individual-level characteristics that were not used to create the matches, using data which were assimilated by us from official statistics. Importantly, these characteristics include the primary outcome, infant mortality. Tests for balance indicate that the 
treated and matched-controls are balanced on characteristics, which validates the matching procedure. We also show the standardised difference between the treatment group and the rest of Sweden (labelled "control"), which suggests that the treated regions were, as the implementers of the intervention intended, representative of Sweden, and this corroborates the external validity of our results.

Panel C of Table 2 makes the same comparison for the 1930 means of some additional variables related to the availability of public services: institutional delivery, weeks of compulsory schooling, years of compulsory schooling, and secondary school enrolment. All four variables exhibit substantial variation between areas and strong trends within the affected cohorts - and they could thus possibly confound our estimates. However, the parish matching algorithm is relatively successful also for these contextual variables: all the three variables for which national averages are available exhibit large improvements in match quality. For secondary schooling enrolment, we do not have national averages, but the difference between treated and control areas is negligible. However, some discrepancies in hospital delivery and compulsory schooling remain also after the matching procedure. In order to safeguard against these variables confounding our results, we included them as controls in our richer specifications, alongside the number of weeks of schooling. The secondary enrolment variable was not considered as a control since it may possibly be affected by the intervention - a possibility we explore in Section 5.9 below.

\subsubsection{Pre-Intervention Trends, Timing and Placebos}

Trends in infant mortality prior to the intervention for an extended time period stretching back to 1910 are shown in Figure 3 for treated and control regions, and there is no evidence of differential pre-trends. The figure also displays an estimate of how linear trends between treated and control areas deviate from each other $(\Delta \beta)$ during this period. The estimate of 0.13 is small and implies that over the 20 -year period considered in the figure, the treatment and control areas would have deviated by 2.6 deaths (confidence interval ranging from -9 to 14.36) compared to a baseline level of around 76 infant deaths per 1,000 population.

We may still be concerned that the effects that we attribute to the infant intervention arise from a contemporaneous intervention that we fail to control for. This concern is mitigated by the fact that the intervention ran for less than two years. Our perusal of the historical literature indicates no other contemporaneous health programs implemented with the same geographic focus. We nevertheless conduct an event study analysis that uses the exact timing of the infant intervention, as it is hard to imagine that there was an exactly overlapping intervention. We also analyse data for individuals who were born after the infant intervention ended and so will not have been exposed to it but who are likely to have bene- 
fited from trend improvements in health in the treated parishes. In addition we control for whether the individual in our sample is a hospital birth to account for a trend in hospitalisation during the period.

Figure 4 provides an event study graph (Jacobson et al., 1993) for the main outcome variables together with the average eligibility in each birth quarter. It also shows confidence intervals for the infant mortality estimates. It is clearly indicative of the programme having an impact which is roughly proportional to eligibility. However, the estimates are relatively noisy, in particular towards the end of our sample. In order to gain more conclusive evidence of causality driving our estimates, we also conducted a permutation test based on the research design. Since each treated parish was matched to a control parish, it is possible to conduct randomisation inference by assigning a placebo treatment within each parish pair (cf. Abadie et al., 2012; Karlsson and Pichler, 2015, for a discussion of randomisation inference in DID designs.). We conduct such a placebo analysis for all outcome variables using 5,000 permutations from which a distribution of placebo 'treatment effects' was derived ${ }^{26}$ Figure 5 plots these distributions for the main outcome variables, along with information regarding the actual treatment effect and the corresponding $p$ value. The inference based on this exercise is similar to the initial results we presented in Table 1 .

In addition, we sampled births from the parishes in our study from five different post-intervention cohorts, born 1940-44. The information in this new dataset is more limited than in the main sample, the only covariate available apart from birth date, parish of birth and date of death is the individual's sex because rather than coming from digitised parish records, data is drawn from demographic information in the 1950 micro-census and the Swedish Death Index. However, we have seen that, in the main analysis, the addition of covariates does not make a significant difference. Using the post-intervention sample, we defined a placebo treatment based on the assumption that the programme was initiated ten years later, in 1941. Results are provided in Table 3 for survival rates to given thresholds as in the initial analysis, except that now we have information on survival up until age 69 rather than age 75 . The estimates are, in general, small and do not approach statistical significance.

\subsubsection{Anticipation, Persistence, Selection}

In this section we deal with three issues which could represent challenges to the clean identification of causal effects of the intervention. First, in reaction to announcement of the intervention, (potential) parents may have changed their fertility decisions. If this behavioural response was selective in ways

\footnotetext{
${ }^{26}$ The placebo treatment was determined in 57 separate draws for each parish pair, and the 5,000 iterations were chosen so as to get a smooth distribution of estimates.
} 
related to our outcomes, it will affect our estimates of the impact of the intervention. Our estimates would still have a causal interpretation, but they would show the combination of two causal effects changed fertility decisions and direct effects of the services - and it would be difficult to disentangle the two.

Second, we test for persistence of programme effects after its discontinuation. If knowledge disseminated during the programme has persistent effects, for example, on younger siblings of exposed mothers, then children born after the intervention are not a valid control group, and the total effects of the programme are larger than the estimated effects.

A third issue is that eligibility for the intervention may be correlated with relevant unobservables. If this is the case, our estimates may be biased. As we argue above, the design of the trial - with "randomly" chosen locations and uniform dates of initiation and discontinuation of the services - and the combination of matching, DID, and regression adjustment that we use, makes this unlikely. We nevertheless provide a further check on this issue by estimating the programme 'impact' on observables that should not be affected by the intervention. These include birth rates, the marital status of the mother, uptake of a pre-existing midwifery programme, a dummy indicating birth in a hospital (as opposed to home), and whether the parish (or city) adopted one of two school reforms that our sample cohorts were exposed to in their school-going ages.

The Parliamentary decision to implement the programme was announced in May 1931 and the programme was effective October 1931. In order to address the possibility of anticipation effects that may have led families to change the timing of fertility, we define a new treatment variable, capturing the time period during which information on the intervention was in the public domain, which is 1 for an individual born 1 April 1932 to 15 November 1933, and 0 otherwise. The idea is that children who were born on the first of April 1932 were the first that could have been conceived after the May 1931 announcement if we allow a month to conceive. Likewise, there was a limited incentive to time a birth to occur after 15 November 1933, since these women and births would be covered during less than half of the pregnancy, and ineligible for the infant care services.

So as to test whether children born after the intervention ended are a valid control group, we define a second new variable which identifies these cohorts. We interact both variables with an indicator for treated parish (or city). To investigate whether anything else was going on that coincided with the infant programme and changed the composition of births, we also estimate regressions including the "usual" treatment variable, measuring exposure to the infant programme.

Results are in Table 4. We find no evidence of endogenous heterogeneity in fertility responses to 
the programme by age of mother, her wedlock status or the occupational status of the father (coefficient on Treated parish $\times$ Cohort exposed to the announcement, Panel A). Since we use women with at least two births in the sample in the mother fixed effects models, we investigate endogenous selection of these women by testing whether the probability of having a further birth after the index birth was a function of programme variables, and this is not the case. We used district medical records to analyse the (quarterly) birth rate in the local area and the (annual) percentage of births attended by a midwife (cf. PetterssonLidbom, 2014) and an indicator for the individual birth was delivered in hospital . We find no evidence of changes in fertility levels, access to midwives or hospitalization of birth (Panel B) ${ }^{27}$ Overall, the absence of anticipation effects on fertility is consistent with the fact that, when announced, the programme was expected to end in 18 months, and an announcement lead time of 4-5 months is not a lot for adjustment of fertility timing.

Coefficients on the indicator for post-intervention cohorts (Treated parish $\times$ Cohort born after the end of the programme) are statistically not significantly different from zero, except for hospital births, which appear to be significantly less likely in treated areas after the intervention. The difference is small in magnitude and would possibly not survive a correction for multiple testing, but we nevertheless include hospital birth as a control variable.

Finally, we test whether the infant programme coincided with changes in the level or composition of births, and whether it was correlated with other welfare reforms. Panel A shows that the infant programme coincided with a decrease in the proportion of in-wedlock births of 2.2 percentage points (2.5 per cent), relative to a mean of $89 \%$. This is not a pre-programme difference between the treatment and control group as our tests of the matching procedure confirm balance on this characteristic. It suggests that the composition of births shifted towards higher-risk births during the programme, which will downward bias our estimates of causal effects of the programme on survival. In the next section, we estimate impacts separately for in-wedlock and out-of-wedlock births, and other sub-groups.

There are no other significant associations in the third row of Table 4. In particular, the last four columns in Panel B show that there were no statistically relevant differences in the local provision of schooling between treated and control areas ${ }^{28}$ The school reforms were implemented several years after the intervention, and so cannot directly confound the estimates but we looked into this to allow that the

\footnotetext{
${ }^{27}$ In panel B, for completeness, we also display impacts of programme announcement on "future" variables marking two school reforms at the parish $\times$ year level, variables that are of interest for the second (balancing) concern indicated above. As we would expect, there is no association between programme anticipation and reforms implemented some years later. The discrepancies in "baseline" between Table 4 and Table 2 are mainly due to seasonal fluctuations in the variables: in Table 4 we use the exact daily (quarterly) definition of the baseline period, whereas Table 2 uses the baseline year 1930.

${ }^{28}$ Extensions of the length of the school year and the introduction of 7 years of compulsory schooling are not related to programme exposure.
} 
infant programme may have shaped local public opinion and made the subsequent school reforms more likely. Fischer et al. (2013) show that the school reforms, which varied by parish, increased longevity. If the infant reform had a causal effect on the adoption of the school reform at the parish level, then exposure to the school reform may be a mechanism by which the infant reform influenced longevity. Our estimates reject this pathway. In Section 5.9 .3 below, we examine school attainment (enrollment to secondary school) as a pathway.

\subsection{Treatment Effect Heterogeneity}

In this section we explore the impact of the infant care intervention in different population subgroups, identified as those among whom we may expect to find elevated risks of infant mortality (see Table 5). As we estimate intent to treat effects, any difference in impact will reflect both "treatability" and differences in take-up. Below we show that take-up does not, in general, vary significantly across the groups we consider.

We first examine whether the programme had different impacts for children born in and out of wedlock because children born out of wedlock were a particular concern among policymakers involved in instituting the programme and they continue to be a concern today, for instance, they have worse indicators at birth than other children (Currie and Rossin-Slater, 2015). We find significantly larger programme impacts for out-of-wedlock births. A child with the average duration of exposure is estimated to have experienced a reduction in infant mortality risk of 6.91 percentage points, which is close to $70 \%$ of the pre-intervention infant mortality rate of 9.9 percent in this group. By the age of 75 , the cumulative effect is as large as 11.44 percentage points, which is a reduction of almost $30 \%$ of the baseline risk. This suggests substantial post-infant survival gains although, as for the population average, the difference in the point estimates is not statistically significant.

We defined "young mothers" as mothers who, at the time of birth, were in the bottom third of the age distribution, below the age of 25.8 years at the index birth. There is some evidence that they benefited more than older mothers from the intervention, although in this case, there is no persistence in the advantage accruing to exposed births beyond the age of five ${ }^{29}$ We then analysed impacts for women

\footnotetext{
${ }^{29}$ This difference in our findings for women who give birth young vs women who give birth unmarried may suggest that births out of wedlock suffer lower investments over the lifecycle while births to younger women have different survival prospects for primarily biological reasons- which are evident early in life but then fade. Without further investigation, however, it is hard to be certain. The pre-intervention infant survival rates for younger women were on average better, so a likely explanation of the larger benefit to children of younger women is that they are much more likely to have been first births, and first born children are known to face higher mortality risks. We could in principle investigate this by studying heterogeneity by age of mother conditional on birth order (parity) and by birth order conditional on age, but we do not have information on birth order in our data.
} 
who were recorded in the data as having experienced a child death before the programme was introduced, because previous research has shown that children who have an older sibling who has died are at much greater risk of dying young (see Arulampalam and Bhalotra, 2006; Bhalotra and Soest, 2008). We find a significant difference in child survival for this group which appears to be reinforced after childhood, leading to larger chances of surviving to age 75 .

There is no statistically significant difference in programme impact by child sex - neither for survival to age five when we might expect larger impacts for boys as they have higher baseline risks (Waldron, 1983), nor for survival to age 40 when we may have expected larger gains for girls if treated girls were less likely to suffer death during childbirth. We examine heterogeneity in impact by the infant mortality rate in the mother's birth year and parish, on the premise that this proxies disease conditions in her birth year (Bozzoli et al., 2007) and so reflects the stock of her health which is relevant to the survival of her births (Andreella et al., 2015; Bhalotra and Rawlings, 2011). We find no evidence that this matters for programme impacts or even for baseline survival chances. Finally, as the trial years coincided with the Great Depression, we created an indicator for parishes disproportionately affected by the Great Depression, defined as the drop in local taxable earnings being larger than the median. We find no difference in impact in these as opposed to less affected parishes.

We also considered heterogeneity between children differently exposed to some of the most important public interventions affecting the sample cohorts. In the bottom panel of Table 5, we interact treatment with a dummy for hospital births, a dummy for the average school year length in grades 1-6 being more than 38.5 weeks, and a dummy for extension of compulsory schooling beyond six years. Since the children in our sample were exposed to the two school reforms after the age of five, the school reforms cannot have influenced infant and child mortality for them, so these can be seen as placebo estimates. The interaction terms are not significant in any case. However, in terms of signs and magnitudes, the results are consistent with the extension of compulsory schooling being complementary to our intervention in its impact on adult mortality.

In conclusion, the evidence indicates that the intervention was successful in reducing health inequalities insofar as relatively vulnerable individuals experienced disproportionately large survival gains. Given evidence that early life health improvements translate into higher levels of education and income in adulthood (Almond, 2006; Bleakley, 2007; Cutler et al., 2010; Lucas, 2010; Bhalotra and Venkataramani, 2011; Bütikofer et al., 2015) it seems likely that the programme also led to a narrowing of economic inequalities. 


\subsection{Programme Utilisation}

The estimates discussed thus far are of intent-to-treat effects, which is what most studies in this domain deliver and which is what matters for policy when a programme with voluntary enrolment is considered. It is nevertheless of interest to study variation in utilisation among the enrolled and, in particular, how this was graded by socioeconomic status as this may contribute to determining where in the distribution programme gains lie, and to a better understanding of mechanisms. Rather unusually, we have access to detailed information on service utilisation, measured at the child level as number of visits received at home, plus number of visits to a clinic to see a nurse or doctor. We regress this upon eligibility and various other covariates in order to assess the selectivity of uptake.

The results are in Table 6. We report results for a binary indicator of enrolment (column 1) and for a the continuous variable capturing the total number of visits (coulmns 2-4). We model utilisation conditional on enrolment (i.e. removing cases of zero visits for eligible children) to focus upon intensive margin responses in column 3. In column 4 we present a first stage regression of number of visits (including zero visits) on duration of treatment eligibility. Column 4 includes both eligible and control cohorts and parishes but, in columns 1-3, the sample is restricted to eligible individuals so that we can assess the socioeconomic gradient in take up amongst those who were eligible. As we may expect, the duration of treatment eligibility is a powerful determinant of treatment intensity (utilisation). However, there is no systematic evidence of a socio-economic status gradient in utilisation.

\subsection{SLS Estimates}

We estimated the impact of actual utilisation on survival rates using two stage least squares and we show estimates using first enrollment (0/1) and then utilisation (number of visits including the zeroes), instrumented with eligibility (0/1) and duration of eligibility. See Table 7 , where the $F$ tests in the lower panel indicate that our instruments are sufficiently strong 30 Enrolment in the infant care intervention is associated with a reduction in infant mortality of 6.6 percentage points, and a marginal change in utilisation (an additional visit) is associated with a reduction in infant mortality of 1.1 percentage points. The pattern of results for survival beyond infancy is similar to the pattern of ITT effects, the coefficient on enrolment dipping slightly but insignificantly for survival to ages 5 and 40 but rising to $9.1 \%$ percentage points for survival to age 75. The coefficients on number of visits are sizeable and follow the same pattern of rising for the age 75 threshold, but they are less well-determined for post-infant survival.

\footnotetext{
${ }^{30}$ We report the statistic for a standard $F$ test and also the variable-specific statistic as suggested by Angrist and Pischke (2008). The negative coefficients on eligibility in the first stage are intercept effects, the coefficients on duration indicate increments in utilisation with duration and these are positive.
} 


\subsection{Parental Investments}

There is considerable interest in the extent to which parental behaviour reinforces or compensates acts of nature or the state (Almond and Mazumder, 2013). If parental investments made during or after the programme reinforced the improvement in infant health created by the intervention, then they will have contributed to the divergence of the trajectories of treated and untreated individuals. We investigate this using sibling data and using matching to control for fertility or birth-spacing effects.

We select older siblings of index children, focusing on children born before 1 October 1930 who were ineligible because they had crossed infancy when the programme was introduced on 1 October 1931. Amongst this group, we compare those with and without younger siblings born in the eligibility period. Our sample contains 846 children who were ineligible but had an eligible younger sibling. We match each of these children to three other individuals born in the pre-intervention period: one born in a treatment district but with no eligible younger sibling, a second born in a control district with an eligible younger sibling and a third born in a control district without an eligible younger sibling. The matching procedure was executed with replacement and based on a propensity score. The propensity score was estimated using the birth date, the mother's age and marital status, socioeconomic group of the household head and the maternal disease environment. Table C.15 presents averages of these covariates for the four groups.

By comparing pre-intervention children in the treated and control areas, we estimate the effect of having a younger sibling who was eligible for the infant-care programme. By comparing with control areas, we get rid of 'normal' differences between children with and without younger siblings, including a tendency for children with a sibling in our sample to be closely spaced. The double difference then captures the effect of the younger sibling's eligibility for services. See Figure 7. The DID estimate indicates a survival disadvantage for children with an eligible younger sibling of at least two percentage points, which manifests itself during the first years of life and persists for at least two decades. The effect kicks in around the time when the younger sibling becomes eligible for the services (typically by being born, or on the 1 October 1931 if born before that date). This suggests that parents may have reinforced the improved health of the index child at the cost of resources expended on the older child. This is consistent with theory (Heckman, 2007; Cunha and Heckman, 2007, Becker and Tomes, 1976) and empirical evidence (Bhalotra and Venkataramani, 2013, Chay et al., 2009). It may also explain why the coefficients estimated with mother fixed effects are larger (though not significantly larger) than coefficients estimated without mother fixed effects. We conducted a similar analysis of impacts on younger siblings of eligible children and found no significant difference, which we interpret as consistent 
with learning effects from an intervention that had a large information component.

\subsection{Mechanisms}

The previous sections have demonstrated that the intervention was associated with a large and significant reduction in infant mortality and with additional effects on adult mortality. In this section, we probe mechanisms driving these results. We analyse cause of death in childhood and in late adulthood, and we investigate endogenous increases in schooling as a potential behavioural mechanism. We have already analysed fertility, which does not appear to be a pathway.

\subsubsection{Childhood Death Causes}

The death cause classification is based on the original parish records, which we used to merge deaths into the five broader classes shown; see Table 8 . We find that the programme significantly reduced childhood deaths assigned to pre-term birth, low birth weight and congenital malformations (we refer to this as ' $L B W$ etc' for brevity in the table). These death causes were responsible for about a third of all infant deaths, and almost the entire programme effect. This finding suggests that enhanced postnatal care successfully prevented deaths of children who were most vulnerable at birth. Home visitors emphasised breastfeeding, clean water baby formula and basic hygiene which are protective for vulnerable babies. Trained home visitors will have monitored the infants' conditions and as mothers were additionally invited to bring babies to clinics for check-ups, the intervention will have facilitated early detection of risks and earlier referrals for treatment. Disaggregating by child sex suggests larger reductions in deaths from ' $L B W$ etc' for males (significant at the ten per cent level), consistent with a vast literature indicating the greater fragility of males at birth which makes it plausible that their infant mortality rates exhibit greater responsiveness to the intervention (Gluckman and Hanson, 2004) ${ }^{31}$

We find no significant change in the risk of death from tuberculosis or pneumonia. TB accounted for a very small share of child deaths, but pneumonia was highly prevalent among newborns. However, large and sharp reductions in infant death from pneumonia (and other bacterial infections) did not occur until the introduction of antibiotics (in 1938 for pneumonia and post-WW2, around 1950 for TB); see Bhalotra and Venkataramani (2011). Also it was very likely the case that children born premature, with low birth weight or congenital defects, were more likely to develop respiratory infections soon after birth

\footnotetext{
${ }^{31}$ Our findings here are consistent with our earlier finding that impacts on infant survival of the postnatal intervention dominated impacts of the antenatal intervention, since findings here indicate that the observed improvements in infant survival were conditional on fitness at birth; see Lee et al. (1980) who make a related point in their analysis of trends in neonatal survival in the United States.
} 
and that assignment of cause of death in these cases may have been to birth weight or prematurity even if the proximate cause was, for example, pneumonia.

Importantly, we find no impact of the intervention on 'External' causes of death under the age of five, a category dominated by accidents and criminal acts directed at children, which in principle makes it a useful placebo category ${ }^{32}$. More than 40 per cent of all infant deaths were categorised as being of 'unknown' cause, reflecting the difficulties of disease and death surveillance in the early twentieth century.

Overall, our finding that the intervention was effective in improving survival chances for children who were frail at birth is in line with the emphasis of the programme on improved nutrition and hygiene and on preventive more than curative care. It also implies that the intervention led to negative selection of survivors, so that our estimates showing reduced death from chronic disease and, thereby, increased longevity, are biased downwards.

\subsubsection{Adult Death Causes}

In order to investigate whether reductions in deaths from chronic disease were a mechanism by which the infant intervention raised longevity, in Table 9 we model cause-specific mortality rates during the age interval 50-75, based on official death cause statistics and the ICD classification ${ }^{33}$ Among individuals exposed to the infant intervention, we find large reductions in mortality from cancer, cardio-vascular disease and infections. The first two together accounted for $58 \%$ of all deaths in this age group in the pre-intervention cohorts. Importantly, we find no significant programme effects on external causes of mortality, such as accidents or assaults, which act as a placebo since one would not expect infant exposure to the intervention to modify deaths from these causes.

We allowed the estimates to differ by sex. See Panel B. There are no sex differences in the absolute reduction in all-cause mortality. However, the proportional reduction is larger for women given their lower baseline risk, and programme effects are distributed differently over death causes for men and women. Accounting for heterogeneity by sex improves the precision of the estimates.

Cardio-vascular deaths decline significantly only among men, by $1.92 \%$ points. The pre-intervention prevalence of cardio-vascular deaths was about three times as high for men as for women, accounting for

\footnotetext{
${ }^{32}$ We do see a small intervention effect on external causes in infancy which we might attribute to home visits leading to fewer accidents and injuries. If there was a direct impact of home visiting nurses averting injury then it makes sense that this effect is dissipated for under-5 mortality since the home visiting only lasted through infancy. In contrast, intervention impacts on particularly frail children persist from infancy through to under-5 mortality

${ }^{33}$ Unconditional estimates for survival to age 75 were presented earlier. Here we condition on survival to age 50 so as to focus on chronic disease which only appears at later ages.
} 
more than a third of all male deaths, and only a fifth of all female deaths, which suggests that men were more "treatable" for $\mathrm{CVD}{ }^{34}$ Cancer deaths declined only among women, by a striking $3.46 \%$ points, accounting for all of the all-cause reduction in deaths among treated women. The pre-intervention prevalence of cancer was similar in absolute terms for men and women but women may have been endogenously more treatable because more women than men survived cardiovascular death to achieve exposure to cancer (see Honoré and Lleras-Muney, 2006, who discuss competing risks in general). Infection-led deaths declined for both men and women, though more for men (by 0.65 vs. $0.05 \%$ points). Deaths from respiratory causes declined more for women but the decline is not statistically significant for either sex.

For the three death causes that are statistically significant in driving intervention-led reductions in adult mortality, we disaggregated into finer causes. Although these estimates are imprecise, it seems clear that there was a substantial reduction in cancers of the lower gastro-intestinal tract, amongst which the most prevalent is colorectal cancer. The estimates for causes within infections and cardiovascular disease do not provide much guidance, though it seems possible to rule out cardiac arrest.

Recent research in economics has linked cardiovascular disease to early life health (Barker, 2012, Hjort et al., 2014; Bütikofer et al., 2014; Van den Berg and Modin, 2013). Importantly, there is medical evidence that breastfeeding (Horta and Victora, 2013) and childhood nutrition (Kinra et al., 2008), which were important components of the programme we study, have been shown to influence adult cardiovascular risk. Reduced adult mortality from infectious disease may be attributable to the programme having contributed to better developed immune systems. We were unable to find much evidence linking early life health to cancer, at least in the economics literature, so we explored this further.

Colorectal cancer is particularly interesting in this context as it is typically sporadic, with more than 95\% of colorectal cancers arising in individuals without a significant hereditary risk. The strongest environmental risk factor is dietary, with fresh fruit and vegetables, milk and dietary fibre thought to be protective (Watson and Collins, 2011). Dietary factors reduce cancer risk through a variety of mechanisms, including a direct impact on inflammation, and indirect effects via obesity (Song et al., 2015). Breastfeeding and proper preparation of milk formula may also be important mediators. Medical evidence suggests that the use of contaminated water for formula increases the risk of gastric diseases (Huffman and Combest, 1990; Mahmood et al., 1989). Moreover breastfeeding promotes certain probiotics which have been documented to reduce the risk of gastrointestinal infection and inflammation (Stark and Lee, 1982, Harmsen et al., 2000).

\footnotetext{
${ }^{34}$ Data published by the National Board of Health using the ULF surveys of 1980, 1988, 1996 and 2004 show that about 30\% of all men born in the 1930's report never having smoked in contrast to $60 \%$ of women. This is possibly one reason.
} 
A study of Asian countries found that changes in cancer prevalence were observed after the nutrition transition associated with the introduction of Western diets (Zhang et al., 2012), but this study is observational and it suggests a decade between dietary change and cancer, which is shorter than the time between infancy and age 50, which is of interest to us. The time of exposure considered in the aforementioned biomedical studies (with exposure typically less than 20 years, cf. Garland et al., 1985) is also shorter than the exposure period covered in this paper. Thus there appears to be no previous evidence indicating a link between nutrition in infancy and adult cancer risk. Not only do our results suggest this, they suggest somewhat remarkably large effects. Averaging over men and women, we estimate that the average duration of eligibility for the infant programme led to a 30 percent reduction in cancer mortality in adulthood. In contrast, Bailey and Goodman-Bacon (2015) estimate that community health centres introduced in the US in the 1960s led to a 1.8 percent reduction in cancer deaths, which they argue may reflect increased longevity due to earlier detection of cancer risk among adults. This suggests that further research into the infant origins of cancer is merited.

For younger children the programme emphasised the importance of breast-feeding, while also advising mothers on how to properly prepare and use formula with clean water. For children older than six months, the intervention included dietary advice, including supplements (like cod liver oil), fruit juice, and the recommendation of a diet including fibre, vegetables and fresh fruit. The medical literature cited above suggests that these elements of the programme will have reduced gastric diseases. Intestinal flora is thought to build up early in life and inadequate flora increases the risk of intestinal inflammation, which in turn may initiate genetic mutations (Kumar et al. 2015; Rinne et al., 2005). Overall, it is plausible that nutritional improvements in infancy brought by the intervention reduced cancer mortality in adulthood.

The nutritional component of the intervention is likely to have been of particular relevance given historical information about the state of nutrition and disease in 1930s Sweden. A few years before the intervention, a large-scale epidemiological study was started, covering most of Northern Sweden where many of our treated and control parishes are located. The backdrop was the observation by M.D. Martin Odin, head physician at the Umeåhospital in the North, of an elevated prevalence of digestive disorders in the population. During 1929-31, more than 17,000 inhabitants of the two northernmost regions were examined by physicians, and the results of the survey were published in 1934 (Hellström et al. 1934). The final report concluded that a "monotone" diet in the region, consisting mainly of grains and almost completely excluding fruit and vegetables, was likely to have been responsible for the elevated prevalence of digestive disorders. Evidence from national household surveys conducted in 
the 1930's (Socialstyrelsen, 1938, Boalt, 1939) indicates that these dietary deficiencies were evident for young children as well, their daily food intake consisting mostly of white bread, and rarely fruit and vegetables. The prevalence of achlorhydia was found to be many times higher than the level observed in other countries, and this condition was associated with a number of other digestive disorders in the intestine (Hellström et al., 1934).

The studies of the broadly similar infant interventions in Denmark and Norway analyse chronic disease but not longevity. Hjort et al. (2014) measure only cardiovascular deaths and among a sample of individuals who survived till 1980 i.e. who were about age 45 (and still resident in Denmark). Bütikofer et al. (2015) do not observe cause-specific mortality, but they have a measure of cardiovascular risk (in addition to BMI and height) for a sample of individuals who survived till 1967 i.e. about age 35 to 40. Because the survivors are relatively young at the time of measurement, these studies may be unable to capture the later onset of chronic disease or allow for programme-driven increases in the probability of surviving chronic disease. Other studies that examine the early life origins of chronic disease have focused upon childhood exposure to recession (Yeung et al., 2014; Van den Berg and Modin, 2013) or to a pre-school intervention (Campbell et al., 2014).

\subsubsection{Schooling Decisions}

The effects of the infant intervention on longevity may include a behavioural component over and above biological mechanisms to the extent that infant health improvements raise cognitive capacity, adult education and income (Almond and Currie, 2011b), and education and income are effective in averting and treating morbidities (Cutler and Lleras-Muney, 2010; Ettner, 1996). Moreover, the expectation of greater longevity may itself motivate increased investments in human capital by extending the horizon over which payoffs accrue (Ben-Porath, 1967; Soares, 2005).

We collected information on secondary school enrolment from all secondary schools in Sweden. Using immatriculation records from the around 250 secondary schools that were available to these cohorts, we constructed an indicator for enrolment. Taken in grade four (at age 10-11), this was the most important educational decision for the cohorts we consider. Around 20 per cent left the basic primary school after either fourth or sixth grade to proceed to the academic track realskola. Individuals were matched based on names, dates of birth and birth parishes, and since the share of secondary schooling enrollees is similar to national averages available from other sources, we believe that the quality of our data is high.

Table 10 presents the results for the realskola decision. Overall, there is no discernible effect of programme eligibility on secondary school enrollment. However, sex-specific estimates show that the 
intervention increased female enrollment by as much as 3-4 percentage points (around 15 per cent). We find no significant change for males, but the coefficient is of similar magnitude and opposite sign, consistent with secondary education being in fixed supply on the local level (see e.g. Statistics Sweden, 1977) ${ }^{35}$ Our finding that the infant intervention improved infant health, and a literature showing that infant health tends to improve brain development and hence cognitive capacity (Bhalotra and Venkataramani, 2013), makes cognitive ability a potential pathway. We are currently digitising test scores from primary school registers, so exploration of this is left to future work.

In an independent exercise reported in Section 5.5, we interacted exposure to the infant intervention with access to institutional (hospital) delivery and exposure to two school reforms that affected a part of our sample in their school-going years (extension of the school year and extension of compulsory schooling by a year, respectively). The only substantive interaction coefficient is that on extension of compulsory schooling, which is protective for adult mortality, although not precisely determined.

The evidence on whether education influences health and health behaviour in later life is ambiguous. For instance, Lleras-Muney and Lichtenberg (2005) show that more educated people in the US are more likely to adopt drugs recently approved by the FDA and that individuals who do not complete high school are twice as likely to smoke as those who continue to college ${ }^{36}$ The NCHS report that the chronic disease death rate for men with a high school education or less was 2.3-2.5 times that for men with more than a high school education, and Fischer et al.(2013) show that an additional year of compulsory education in early $20^{\text {th }}$ century Sweden reduced mortality risk between school leaving age and age $70{ }^{37}$ On the other hand, Clark and Roayer (2013) find no significant impact of education on health. Similarly, Van den Berg and Modin (2013), who show that being born with low birth weight in a recession is predictive of cardiovascular mortality later in life, find no evidence of cognitive ability or educational attainment as pathways.

Since the gains in longevity that we document are similar for males and females, and the increase in secondary education is unique to females, the only way in which we might rationalize education as a mechanism for the increase in longevity is through arguing that women made many of the relevant decisions within marriage, for instance, about diet and accessing new drugs or medical care. In this case, women's education would spillover to create pan-gender improvements in longevity, but we cannot

\footnotetext{
${ }^{35} \mathrm{We}$ are currently investigating the positive effect for females by coding detailed information on occupational choice, sectorspecific employment expansion and returns to schooling, but this work is on-going and beyond the scope of this paper.

${ }^{36} \mathrm{We}$ do not have information on health-related behaviours for our birth cohorts. Data on smoking and alcohol consumption for instance are only available in surveys with small samples which restrict the possibility of individual matching

${ }^{37}$ Our estimates in Table 5 showed that that children in our sample who were first exposed to the infant intervention and later exposed to extended compulsory schooling benefitted disproportionately from the intervention, although as the interaction term is not statistically significant the evidence remains ambiguous.
} 
conclusively establish this.

\section{Conclusion}

The poor state of reproductive and early childhood health in developing countries is regarded as one of the greatest failures of development. In recognition of this, at the 2010 United Nations Summit reviewing progress towards the Millennium Development Goals (MDGs) for 2015, a sum of over 40 billion USD over five years was pledged to support a Global Strategy for Women's and Children's Health, a concerted worldwide effort initiated by United Nations Secretary-General Ban Ki-moon who said: We know what works to save women's and children's lives, and we know that women and children are critical to all of the MDGs (see United Nations, 2010) ${ }^{38}$ In fact knowledge of causal effects at a population level is limited. We evaluate a rather rare intervention, designed as a non-randomised trial and implemented over a short horizon in the 1930s in Sweden, which emphasised "soft" inputs including information, monitoring and support with a large home-visiting component. The information provided was structured to encourage and support breastfeeding, a nutritious and balanced diet in early childhood and sanitation and the use of clean water, and the home visits and clinical services further assisted in early detection of risks and, where needed, referrals for physician care.

We find large effects on infant survival and, furthermore, on adult mortality after the age of fifty from cardiovascular disease, cancer and infections. Our findings have the potential to influence current global health priorities by highlighting that large gains in infant health and, at no further cost, in chronic disease reduction, may be achieved by a relatively low-cost and scale-able intervention. The findings have wider contemporary relevance as a number of recent programs in, for instance, the USA and the UK, involve targeting high-risk mothers with similar programs and chronic disease is now rampant in both rich and poor countries 9

\footnotetext{
${ }^{38}$ Child mortality is widely used as an indicator of child health, being much easier to measure and track than a host of morbidities.

${ }^{39}$ Today's poorer countries are carrying the double burden of infectious disease and chronic diseases. Three-quarters of all chronic disease related deaths today occur in low and middle-income countries, where many individuals cannot afford the costs of treatment.
} 


\section{References}

Abadie, A., Diamond, A., Hainmueller, J., 2012. Synthetic control methods for comparative case studies: Estimating the effect of california's tobacco control program. Journal of the American Statistical Association.

Aizer, A., Eli, S., Ferrie, J. P., Lleras-Muney, A., 2014. The long term impact of cash transfers to poor families. Tech. rep., National Bureau of Economic Research.

Almond, D., 2006. Is the 1918 influenza pandemic over? long-term effects of in utero influenza exposure in the post-1940 us population. Journal of political Economy 114 (4), 672-712.

Almond, D., Currie, J., 2011a. Human capital development before age five. Handbook of labor economics 4, 1315-1486.

Almond, D., Currie, J., 2011b. Killing me softly: The fetal origins hypothesis. The Journal of Economic Perspectives 25 (3), 153-172.

Almond, D., Hoynes, H. W., Schanzenbach, D. W., 2011. Inside the war on poverty: The impact of food stamps on birth outcomes. The Review of Economics and Statistics 93 (2), 387-403.

Almond, D., Mazumder, B., 2013. Fetal origins and parental responses. Annu. Rev. Econ. 5 (1), 37-56.

Andrabi, T., Das, J., Khwaja, A. I., 2013. Report card: The impact of providing school and child test scores on educational markets. Journal of health economics Mimeograph.

Andreella, C., Karlsson, M., Nilsson, T., Westphal, M., 2015. The long shadows of past insults intergenerational transmission of health over 130 years. Tech. rep., Ruhr Economic Papers.

Angrist, J. D., Pischke, J.-S., 2008. Mostly harmless econometrics: An empiricist's companion. Princeton university press.

Arulampalam, W., Bhalotra, S., 2006. Sibling death clustering in india: state dependence versus unobserved heterogeneity. Journal of the Royal Statistical Society: Series A (Statistics in Society) 169 (4), 829-848.

Bailar, J. C., Gornik, H. L., 1997. Cancer undefeated. New England Journal of Medicine 336 (22), 15691574.

Bailey, M. J., Goodman-Bacon, A., 2015. The war on poverty's experiment in public medicine: Community health centers and the mortality of older americans. The American economic review 105 (3), 1067.

Bandiera, O., Larcinese, V., Rasul, I., 2009. Blissful ignorance? evidence from a natural experiment on the effect of individual feedback on performance. Policy Research Working Paper Series 4122.

Barker, D., 1990. The fetal and infant origins of adult disease. British Medical Journal 301 (6761), 11111111.

Barker, D., 1994. The fetal origins of adult disease. Fetal and Maternal Medicine Review 114 (02), $71-80$.

Barker, D., 2012. Developmental origins of chronic disease. Public health 126 (3), 185-189. 
Barker, D. J., Osmond, C., 1986. Infant mortality, childhood nutrition, and ischaemic heart disease in england and wales. The Lancet 327 (8489), 1077-1081.

Becker, G., Tomes, N., 1976. Child endowments, and the quantity and quality of children. Journal of Political Economy 84 (4, Part 2), S143-S162.

Ben-Porath, Y., 1967. The production of human capital and the life cycle of earnings. The Journal of Political Economy 75, 352-365.

Bhalotra, S., 2010. Fatal fluctuations? cyclicality in infant mortality in india. Journal of Development Economics 93 (1), 7-19.

Bhalotra, S., Rawlings, S. B., 2011. Intergenerational persistence in health in developing countries: The penalty of gender inequality? Journal of Public Economics 95 (3), 286-299.

Bhalotra, S., Soest, A. v., 2008. Birth-spacing, fertility and neonatal mortality in india: Dynamics, frailty, and fecundity. Journal of Econometrics 143 (2), 274-290.

Bhalotra, S. R., Venkataramani, A., 2011. The captain of the men of death and his shadow: Long-run impacts of early life pneumonia exposure. Available at SSRN.

Bhalotra, S. R., Venkataramani, A., 2013. Cognitive development and infectious disease: Gender differences in investments and outcomes.

Bharadwaj, P., Gibson, M., Zivin, J. G., Neilson, C. A., 2014. Gray matters: Fetal pollution exposure and human capital formation. Tech. rep., National Bureau of Economic Research.

Black, R. E., Cousens, S., Johnson, H. L., Lawn, J. E., Rudan, I., Bassani, D. G., Jha, P., Campbell, H., Walker, C. F., Cibulskis, R., et al., 2010. Global, regional, and national causes of child mortality in 2008: a systematic analysis. The lancet 375 (9730), 1969-1987.

Bleakley, H., 2007. Disease and development: evidence from hookworm eradication in the american south. The Quarterly Journal of Economics 122 (1), 73-117.

Boalt, C., 1939. 27.000 måltider: en undersökning av kostvanor. Kooperativa förbundet.

Bozzoli, C., Deaton, A. S., Quintana-Domeque, C., 2007. Child mortality, income and adult height. Tech. rep., National Bureau of Economic Research.

Bütikofer, A., Løken, K. V., Salvanes, K., 2014. Long-term consequences of access to well-child visits. URL https://www.wiwi.hu-berlin.de/professuren/vwl/wtm2/ seminar-schumpeter/kontrollstasjoner_09102014_kjell.pdf

Bütikofer, A., Løken, K. V., Salvanes, K. G., 2015. Long-term consequences of access to well-child visits. NHH Dept. of Economics Discussion Paper (29).

Campbell, F., Conti, G., Heckman, J. J., Moon, S. H., Pinto, R., Pungello, E., Pan, Y., 2014. Early childhood investments substantially boost adult health. Science 343 (6178), 1478-1485.

Chamberlain, G., 2006. British maternal mortality in the 19th and early 20th centuries. Journal of the Royal Society of Medicine 99 (11), 559-563.

Chay, K. Y., Guryan, J., Mazumder, B., 2009. Birth cohort and the black-white achievement gap: The roles of access and health soon after birth. Tech. rep., National Bureau of Economic Research. 
Clark, D., Royer, H., 2013. The effect of education on adult mortality and health: Evidence from britain. The American Economic Review 103 (6), 2087-2120.

Corsini, C. A., Viazzo, P. P., 1997. The decline of infant and child mortality: the European experience, 1750-1990. Martinus Nijhoff Publishers.

Cunha, F., Elo, I. T., Culhane, J. F., 2013. Eliciting maternal subjective expectations about the technology of cognitive skill formation. PSC Working paper series.

Cunha, F., Heckman, J., 2007. The technology of skill formation. Tech. rep., National Bureau of Economic Research.

Currie, J., Rossin-Slater, M., 2015. Early-life origins of life-cycle well-being: Research and policy implications. Journal of Policy Analysis and Management 34 (1), 208-242.

Cutler, D., Deaton, A., Lleras-Muney, A., 2006. The determinants of mortality. Journal of Economic Perspectives 20 (3), 97-120.

Cutler, D., Fung, W., Kremer, M., Singhal, M., Vogl, T., 2010. Early-life malaria exposure and adult outcomes: Evidence from malaria eradication in india. American Economic Journal: Applied Economics, 72-94.

Cutler, D. M., Lleras-Muney, A., 2010. Understanding differences in health behaviors by education. Journal of health economics 29 (1), 1-28.

Davis, A., 2011. A revolution in maternity care? women and the maternity services, oxfordshire c. 1948-1974. Social history of medicine 24 (2), 389-406.

Dupas, P., 2011. Health behavior in developing countries. Annu. Rev. Econ. 3 (1), 425-449.

Engle, P. L., Black, M. M., Behrman, J. R., Cabral de Mello, M., Gertler, P. J., Kapiriri, L., Martorell, R., Young, M. E., 2007. Strategies to avoid the loss of developmental potential in more than 200 million children in the developing world. The Lancet 369 (9557), 229-242.

Ernberg, H., 1930. Råd och anvisningar vid vården av barn, särskilt späda barn. På uppdrag av Medicinalstyrelsen. Kungliga boktryckeriet. P.A. Norstedt och Söner, Stockholm.

Ettner, S. L., 1996. New evidence on the relationship between income and health. Journal of health economics 15 (1), 67-85.

Fildes, V., Marks, L., Marland, H., 2013. Women and children first: international maternal and infant welfare, 1870-1945. Routledge.

Fiscella, K., 1995. Does prenatal care improve birth outcomes? a critical review. Obstetrics \& Gynecology 85 (3), 468-479.

Fischer, M., Karlsson, M., Nilsson, T., 2013. Effects of compulsory schooling on mortality: evidence from Sweden. International journal of environmental research and public health 10 (8), 3596-3618.

Fischer, M., Karlsson, M., Nilsson, T., Ringkvist, J., 2016. A researcher's guide to the Swedish Folkskolereform. Tech. rep.

Fitzsimons, E., Malde, B., Mesnard, A., Vera-Hernandez, M., 2014. Nutrition, information, and household behaviour: experimental evidence from malawi. Tech. rep., IFS Working Papers. 
Frölich, M., Huber, M., Wiesenfarth, M., 2015. The finite sample performance of semi-and nonparametric estimators for treatment effects and policy evaluation.

Garland, C., Barrett-Connor, E., Rossof, A., Shekelle, R., Criqui, M., Paul, O., 1985. Dietary vitamin d and calcium and risk of colorectal cancer: a 19-year prospective study in men. The Lancet 325 (8424), 307-309.

Gluckman, P. D., Hanson, M. A., 2004. The fetal matrix: evolution, development and disease. Cambridge University Press.

Gresham, E., Byles, J. E., Bisquera, A., Hure, A. J., 2014. Effects of dietary interventions on neonatal and infant outcomes: a systematic review and meta-analysis. The American journal of clinical nutrition, ajcn-080655.

Harmsen, H. J., Wildeboer-Veloo, A. C., Raangs, G. C., Wagendorp, A. A., Klijn, N., Bindels, J. G., Welling, G. W., 2000. Analysis of intestinal flora development in breast-fed and formula-fed infants by using molecular identification and detection methods. Journal of pediatric gastroenterology and nutrition 30 (1), 61-67.

Heckman, J. J., 2007. The economics, technology, and neuroscience of human capability formation. Proceedings of the national Academy of Sciences 104 (33), 13250-13255.

Hellström, N., Ankarswärd, G., Byttner, J., Westin, G., Odin, M., Holtz, H., Lindström, A., Götlin, G., 1934. En socialhygienisk undersökning i Västerbottens och Norrbottens län. Håkan Ohlssons Boktryckeri, Lund.

Hjort, J., Solvesten, M., Wüst, M., 2014. Universal investment in infants and long-run health: Evidence from denmark's 1937 home visiting program. Tech. rep., Mimeo.

Högberg, U., 2004. The decline in maternal mortality in sweden: the role of community midwifery. American Journal of Public Health 94 (8), 1312-1320.

Hollowell, J., Kurinczuk, J., Oakley, L., Brocklehurst, P., Gray, R., 2009. A systematic review of antenatal care programmes to reduce infant mortality and its major causes in socially disadvantaged and vulnerable women. National Perinatal Epidemiology Unit, University of Oxford.

Honoré, B. E., Lleras-Muney, A., 2006. Bounds in competing risks models and the war on cancer. Econometrica 74 (6), 1675-1698.

Horta, B. L., Victora, C. G., 2013. Long-term effects of breastfeeding-a systematic review.

Hoynes, H. W., Schanzenbach, D. W., Almond, D., 2012. Long run impacts of childhood access to the safety net. Tech. rep., National Bureau of Economic Research.

Huffman, S. L., Combest, C., 1990. Role of breastfeeding in teh prevention and treatment of diarrhoea. Journal of diarrhoeal diseases research, 68-81.

Hultkvist, G., 1940. Några anmärkningar till vår nya dödsorsaksstatistik. Allmänna Svenska Läkartidningen $17,58-60$.

Hyrenius, H., 1914. Den svenska officiella dödsorsaksstatistiken. Social-medicinsk tidskrift 11, 11791188.

Imbens, G., Wooldridge, J., 2009. Recent developments in the econometrics of program evaluation. Journal of Economic Literature 47 (1), 5-86. 
Jacobson, L. S., LaLonde, R. J., Sullivan, D. G., 1993. Earnings losses of displaced workers. The American economic review, 685-709.

Jones, G., Steketee, R. W., Black, R. E., Bhutta, Z. A., Morris, S. S., Group, B. C. S. S., et al., 2003. How many child deaths can we prevent this year? The lancet 362 (9377), 65-71.

Karlsson, M., Nilsson, T., Pichler, S., 2014. The impact of the 1918 spanish flu epidemic on economic performance in sweden: An investigation into the consequences of an extraordinary mortality shock. Journal of health economics 36, 1-19.

Karlsson, M., Pichler, S., 2015. Demographic consequences of hiv. Journal of Population Economics 28 (4), 1097-1135.

King, G., Nielsen, R., Coberley, C., Pope, J. E., Wells, A., 2011. Comparative effectiveness of matching methods for causal inference. Unpublished manuscript 15.

Kinra, S., Sarma, K. R., Mendu, V. V. R., Ravikumar, R., Mohan, V., Wilkinson, I. B., Cockcroft, J. R., Smith, G. D., Ben-Shlomo, Y., et al., 2008. Effect of integration of supplemental nutrition with public health programmes in pregnancy and early childhood on cardiovascular risk in rural indian adolescents: long term follow-up of hyderabad nutrition trial. Bmj 337, a605.

Kumar, K. S., Sastry, N., Polaki, H., Mishra, V., 2015. Colon cancer prevention through probiotics: an overview. Journal of Cancer Science \& Therapy 2015.

Kungl. Propositioner, 1930. Kungl. Majits proposition 1930: 306.

Lechner, M., Rodríguez-Planas, N., Fernández Kranz, D., 2015. Difference-in-difference estimation by fe and ols when there is panel non-response. Journal of Applied Statistics, 1-9.

Lee, K.-S., Paneth, N., Gartner, L. M., Pearlman, M. A., Gruss, L., 1980. Neonatal mortality: an analysis of the recent improvement in the united states. American Journal of Public Health 70 (1), 15-21.

Leeuwen, M. v., Maas, I., Miles, A., 2002. HISCO: Historical international standard classification of occupations. Leuven: Leuven University Press.

Lindsjö, D., 1934. Den statliga försöksverksamheten "för- och eftervård vid barnsbörd". In: Årsberättelse. pp. 7-25.

Lleras-Muney, A., Lichtenberg, F. R., 2005. Are the more educated more likely to use new drugs? Annales d'Économie et de Statistique, 671-696.

Loudon, I., 2000. Maternal mortality in the past and its relevance to developing countries today. The American journal of clinical nutrition 72 (1), 241s-246s.

Lucas, A. M., 2010. Malaria eradication and educational attainment: evidence from paraguay and sri lanka. American economic journal. Applied economics 2 (2), 46.

Ludwig, J., Miller, D. L., 2005. Does head start improve children's life chances? evidence from a regression discontinuity design. Tech. rep., National Bureau of Economic Research.

Mahmood, D., Feachem, R., Huttly, S., 1989. Infant feeding and risk of severe diarrhoea in basrah city, iraq: a case-control study. Bulletin of the World Health Organization 67 (6), 701.

Moehling, C. M., Thomasson, M. A., 2014. Saving babies: The impact of public education programs on infant mortality. Demography 51 (2), 367-386. 
Murphy, K. M., Topel, R. H., 2006. The value of health and longevity. Journal of Political Economy $114(5)$.

Nordström, L., 1938. Lort-sverige.

Oster, E., 2014. Unobservable selection and coefficient stability: Theory and evidence. University of Chicago Booth School of Business Working Paper.

Petronis, A., 2010. Epigenetics as a unifying principle in the aetiology of complex traits and diseases. Nature 465 (7299), 721-727.

Pettersson-Lidbom, P., 2014. Midwives and maternal mortality: Evidence from a midwifery policy experiment in sweden in the 19th century.

Pischke, J.-S., Schwandt, H., 2014. Poorly measured confounders are more useful on the left than on the right. Tech. rep., Working Paper, London School of Economics.

Razavi, S., 2012. World development report 2012: Gender equality and development-a commentary. Development and Change 43 (1), 423-437.

Rinne, M., Kalliomaki, M., Arvilommi, H., Salminen, S., Isolauri, E., 2005. Effect of probiotics and breastfeeding on the bifidobacterium and lactobacillus/enterococcus microbiota and humoral immune responses. The Journal of pediatrics 147 (2), 186-191.

SCB, S. C., 2015. Dödsorsaksregistret.

Soares, R. R., 2005. Mortality reductions, educational attainment, and fertility choice. American Economic Review 95, 580-601.

Socialstyrelsen, S., 1938. Levnadsvillkor och hushållsvanor i städer och industriorter omkring år 1933. PA Norstedt och söner.

Song, M., Garrett, W. S., Chan, A. T., 2015. Nutrients, foods, and colorectal cancer prevention. Gastroenterology 148 (6), 1244-1260.

Stark, P. L., Lee, A., 1982. The microbial ecology of the large bowel of breastfed and formula-fed infants during the first year of life. Journal of Medical Microbiology 15 (2), 189-203.

Statens Offentliga Utredningar, 1945. Betänkande om förlossningsvården, givet av 1941 års befolkningsutredning. SOU 1945:50, Stockholm.

Statistics Sweden, 1915. Dödsorsaker år 1911. Stockholm: Kungl. Statistiska Centralbyrån.

Statistics Sweden, 1940. Statistisk årsbok för Sverige. Stockholm:Statistiska centralbyrån.

Statistics Sweden, 1977. Elever i icke-obligatoriska skolor 1864-1970.

Steenhoff, G., 1931. Hur nedbringa dödligheten bland de späda barnen? Tidskrift för Barnavård och Ungdomsskydd (7/8), 283-88.

Steenhoff, G., 1934. Försöksverksamhet beträffande för- och eftervård vid barnsbörd. Tidskrift för Barnavård och Ungdomsskydd (3), 99-101.

Stenhammar, A.-M., Ohrlander, K., Mjölkdroppen, F., 2001. Mjölkdroppen: filantropi, förmynderi eller samhällsansvar? Carlsson. 
Swedish Genealogical Society, 2012. Begravda i Sverige 2. Stockholm: Swedish Genealogical Society.

Swedish Red Cross, 1928. Allt för barnet: Korta illustrerade råd och anvisningar i barnavård. Röda korset.

URL http: //books.google.se/books?id=rGCFmQEACAAJ

The National Board of Health and Welfare, 2012. Dödsorsaksregistret. Stockholm.

United Nations, 2010. Global strategy for women's and children's health. URL http://www.un.org/en/mdg/summit2010/

Van den Berg, G. J., Modin, B., 2013. Economic conditions at birth, birth weight, ability, and the causal path to cardiovascular mortality. IZA Discussion Paper.

Waldron, I., 1983. The role of genetic and biological factors in sex differences in mortality. in Lopez, A. D. and Ruzicka, L. T., eds., Sex Differentials in Mortality: Trends, Determinants and Consequences.

Wallgren, A., 1936. Den förebyggande spädbarnsvårdens organisation. Tidskrift för Barnavård och Ungdomsskydd (5), 163-67.

Watson, A. J., Collins, P. D., 2011. Colon cancer: a civilization disorder. Digestive diseases 29 (2), 222-228.

WHO, 2012. Life expectancy. data by country. Global Health Observatory Data Repository.

Wisselgren, M., 2005. Att föda barn - från privat till offentlig angelägenhet. Tech. rep., UmeåUniversity.

Wüst, M., 2012. Early interventions and infant health: Evidence from the danish home visiting program. Labour Economics 19 (4), 484-495.

Yeung, G. Y., Van den Berg, G. J., Lindeboom, M., Portrait, F. R., 2014. The impact of early-life economic conditionson cause-specific mortality during adulthood. Journal of Population Economics 27 (3), 895-919.

Zhang, J., Dhakal, I. B., Zhao, Z., Li, L., 2012. Trends in mortality from cancers of the breast, colon, prostate, esophagus, and stomach in east asia: role of nutrition transition. European Journal of Cancer Prevention 21 (5), 480-489.

Zhao, Z., 2004. Using matching to estimate treatment effects: Data requirements, matching metrics, and monte carlo evidence. review of economics and statistics 86 (1), 91-107.

Ziebarth, N. R., Karlsson, M., 2014. The effects of expanding the generosity of the statutory sickness insurance system. Journal of Applied Econometrics 29 (2), 208-230. 


\section{A Variable Definitions}

\section{A.1 Information from Parish Records}

Infant Mortality $\left(d_{0-1}\right)$ : dummy variable taking on value one for live births who die within a year of birth.

Child Mortality $\left(d_{0-5}\right)$ : dummy variable taking on value one for live births who die within five years of birth.

0-40 Mortality $\left(d_{0}-40\right)$ : dummy variable taking on value one for live births who die within 40 years of birth.

0-75 Mortality $\left(d_{0-75}\right)$ : dummy variable taking on value one for live births who die within 75 years of birth.

Female Dummy variable taking on the value one for female births.

Twin Dummy variable taking on value one for (mono- and dizygotic) twins.

Wedlock Dummy variable taking on value one for children born to married mothers.

Mother's Age The mother's age at the time of birth.

MYoung Dummy variable taking on value one if the mother belongs to the youngest third of mothers (age $<25.8$ ) at the time of the birth.

MOld Dummy variable taking on value one if the mother belongs to the oldest third of mothers (age $>32.3$ ) at the time of the birth

Maternal IMR The infant mortality rate in the parish and year of birth of the mother (defined as deviation from local average and overall time trend). Source: Andreella et al. (2015).

Treated Dummy variable taking on value one for children born in treated areas.

DurationI Duration in months of potential eligibility for infant care intervention.

SES Classification of head of household profession according to HISO 9-point scale (Leeuwen et al. 2002).

Birthrate Births in a quarter per fertile married woman in the parish

Childhood death causes Categorisation based on parish death records.

\section{A.2 Information from Other Sources}

Crisis Parish-level shortfall in taxable incomes per capita compared to 1930 level (\%), measured in the birth year. Source: official tax records.

Midwife Share Proportion (in per cent) of births in health district attended by a midwife. Source: district physicians.

Complications Proportion (in per cent) of midwife-attended births in health district with complications reported. Source: district physicians.

Enrolment Infant Equals one if the child had at least one visit/home call during infancy. Source: official records from the intervention.

Utilisation Infant Number of visits during infancy. Source: official records from the intervention.

Weeks Compulsory Schooling Total number of weeks of schooling during grades 1-6 applying to the individual's birth cohort in the parish of birth. Source: Fischer et al. (2016).

Seven Years Compulsory Dummy variable taking on the value one if the individual's cohort was exposed to 7 years of compulsory schooling in birth parish. Source: Fischer et al. (2016).

Secondary Enrolment Dummy variable taking on the value one if the individual enrolled in secondary schooling. Source: immatriculation records of all secondary schools in Sweden.

Institutional Delivery Dummy variable taking on value one for children born in hospital.

Adult Death Causes Categorisation of adult death causes according to ICD groups; based on the national death cause register (SCB, 2015). 


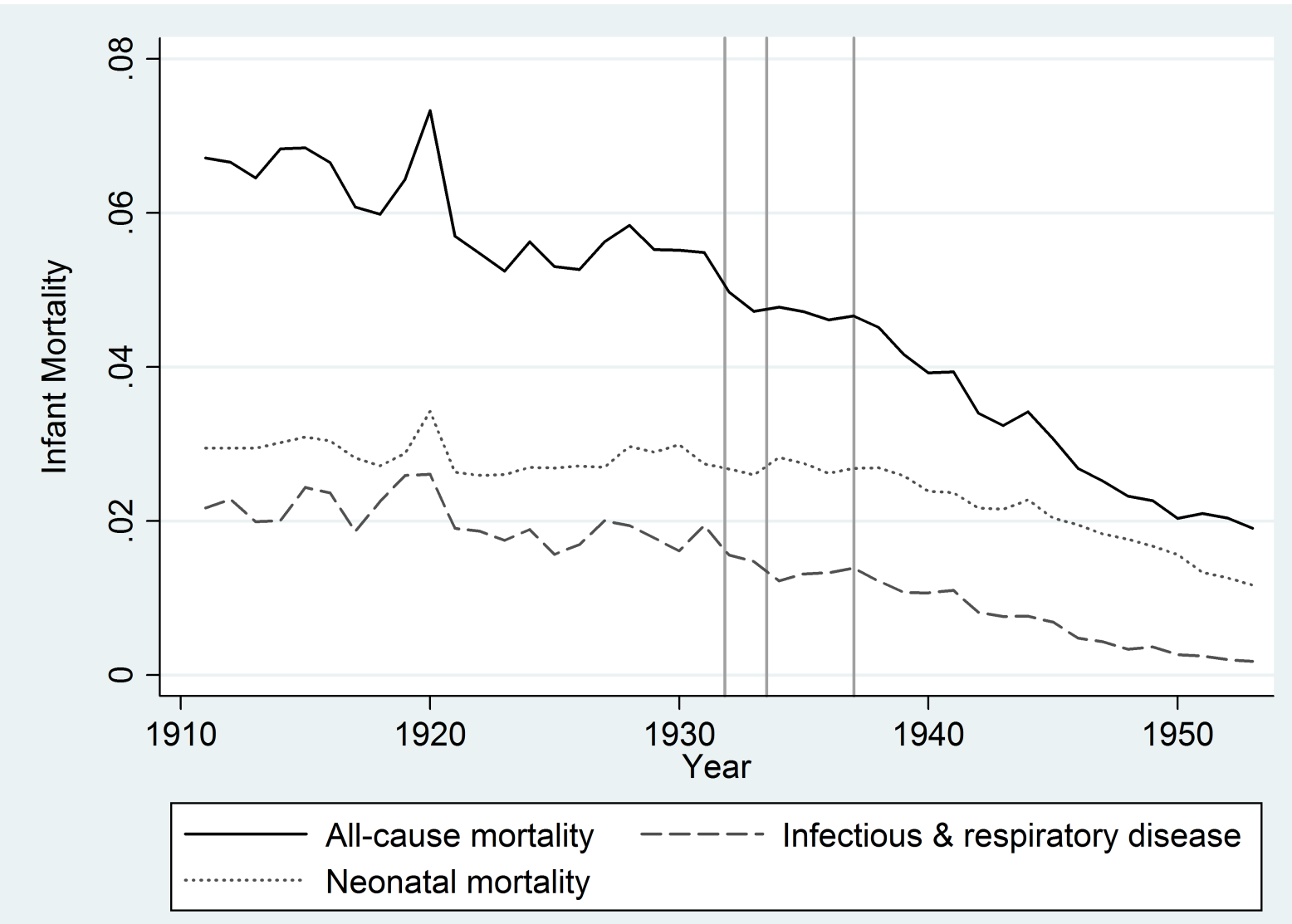

Figure 1. National Infant (All-Cause and Cause Specific) Mortality Rates in Sweden 1910-40.

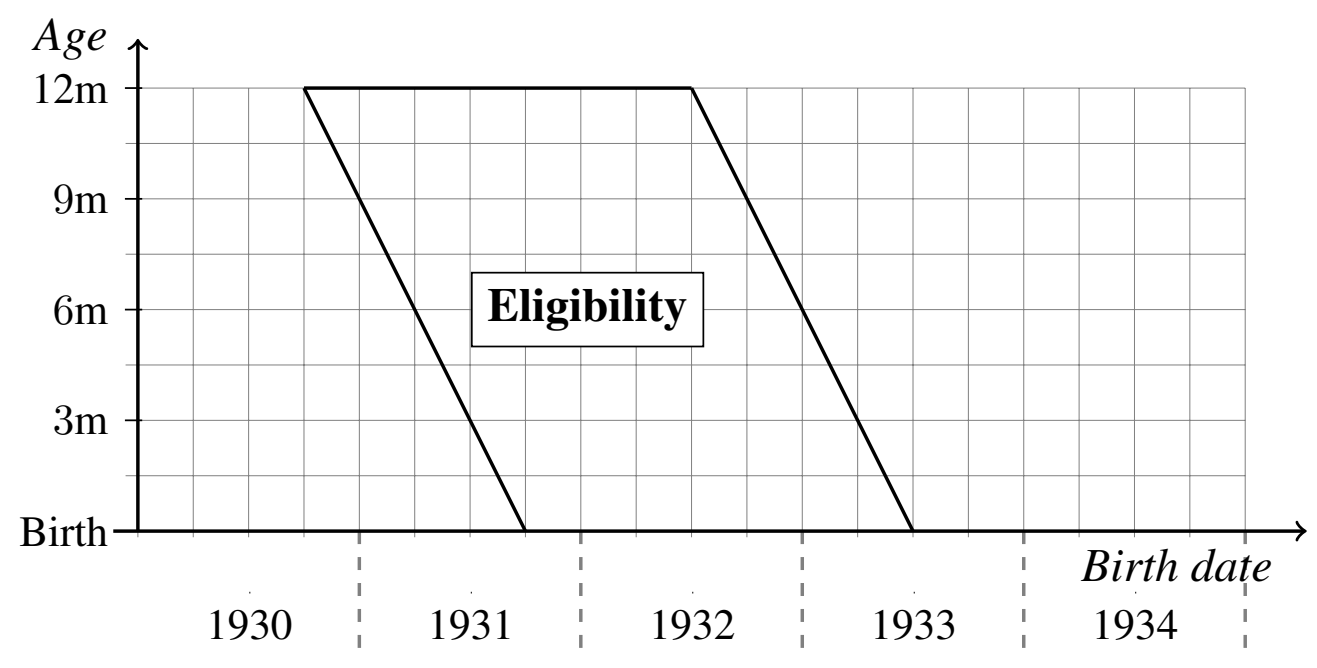

Figure 2. Eligibility at Different Ages of Children Born at Different Dates. 


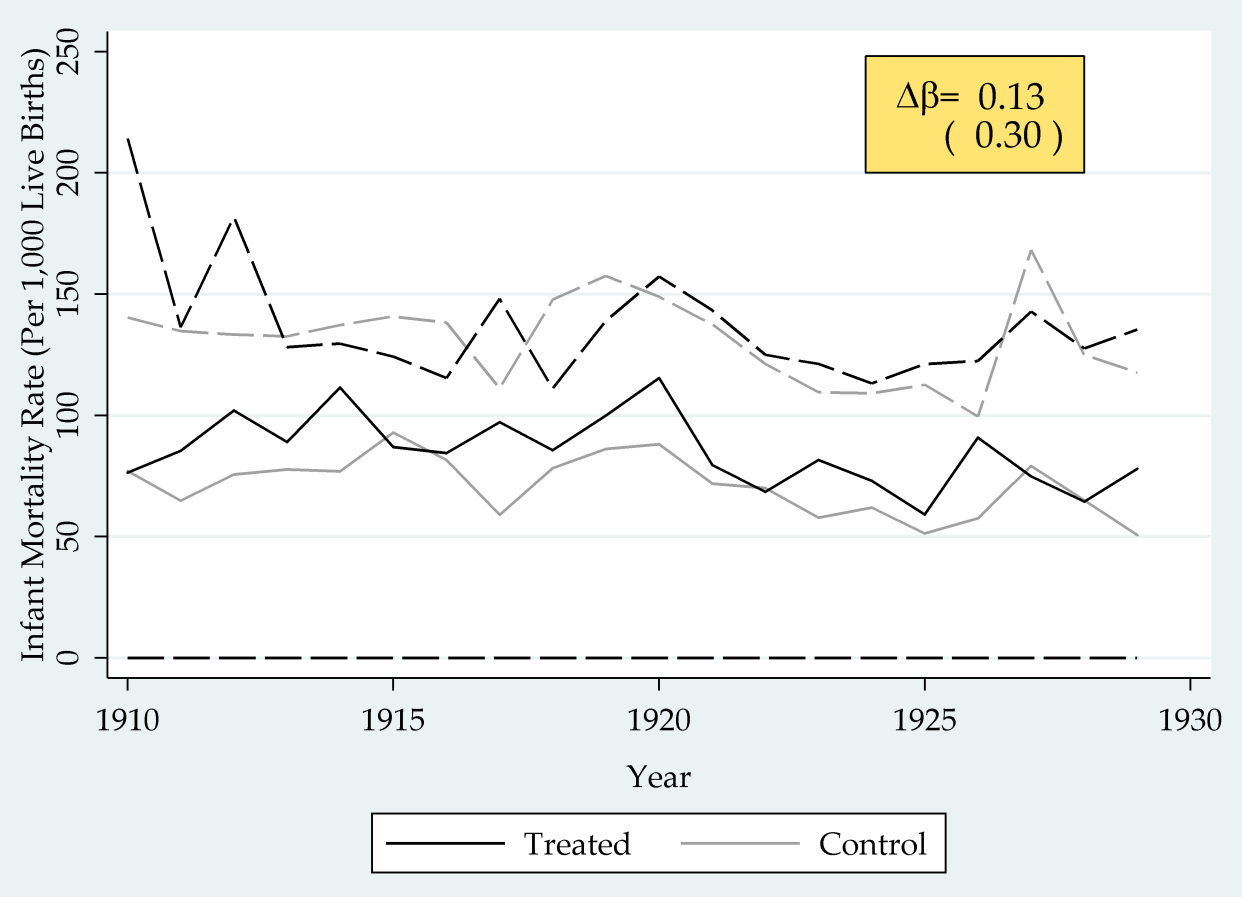

Figure 3. Pre-Intervention Trends in Infant Mortality Rates in Treated and Control locations - Median, $10^{\text {th }}$ and $90^{\text {th }}$ Percentiles. Black lines (solid or dashed) correspond to treated areas, while grey lines (solid or dashed) correpsond to control areas. For the 10th percentile the lines for treated and control areas coincide.

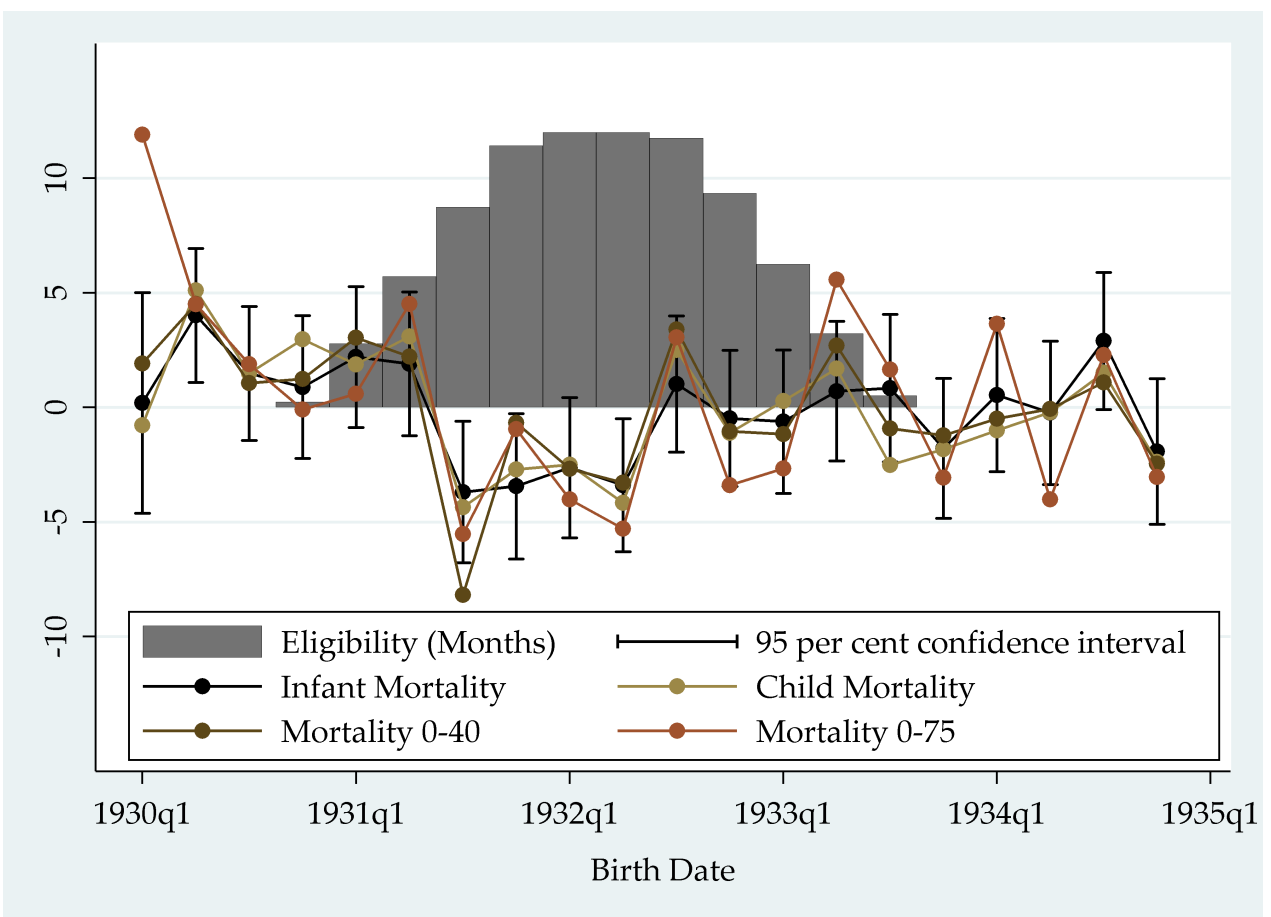

Figure 4. Event Study Graph for Program Impact. 

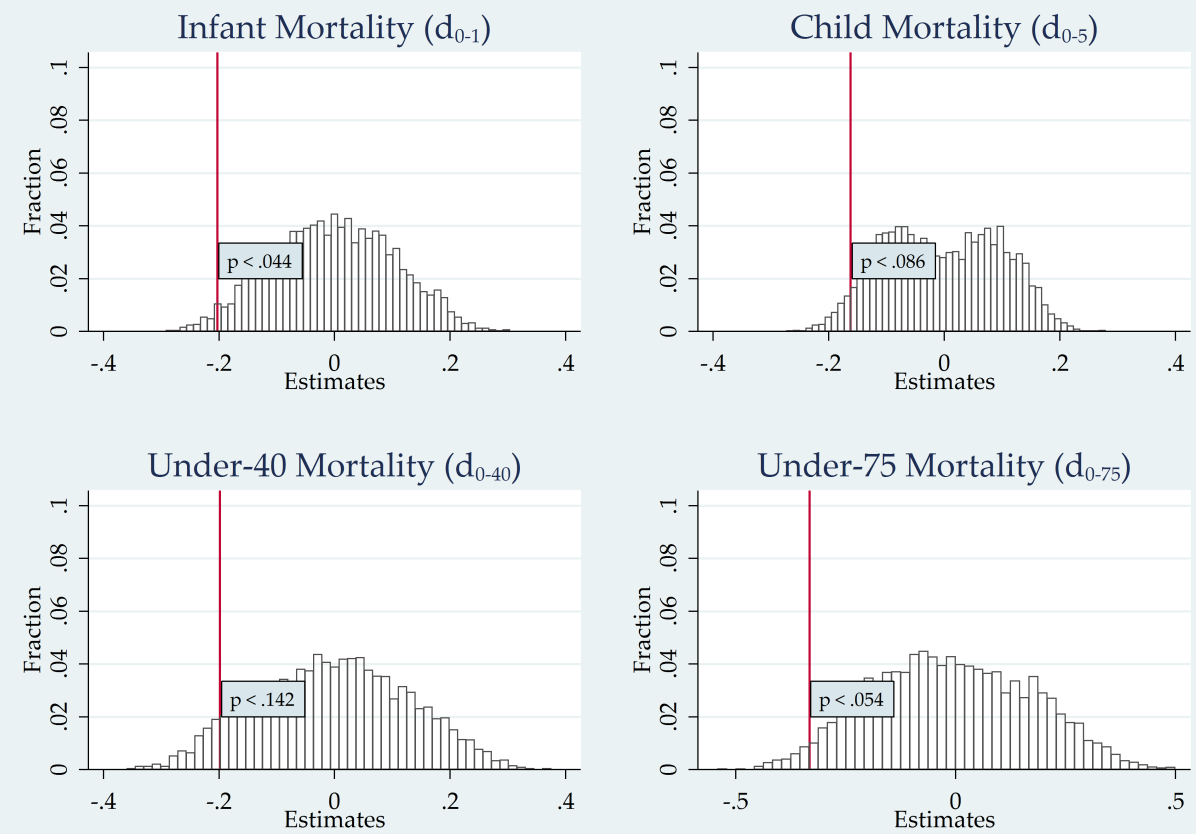

Figure 5. Randomisation Inference based on 5,000 Permutations of Treatment Status.
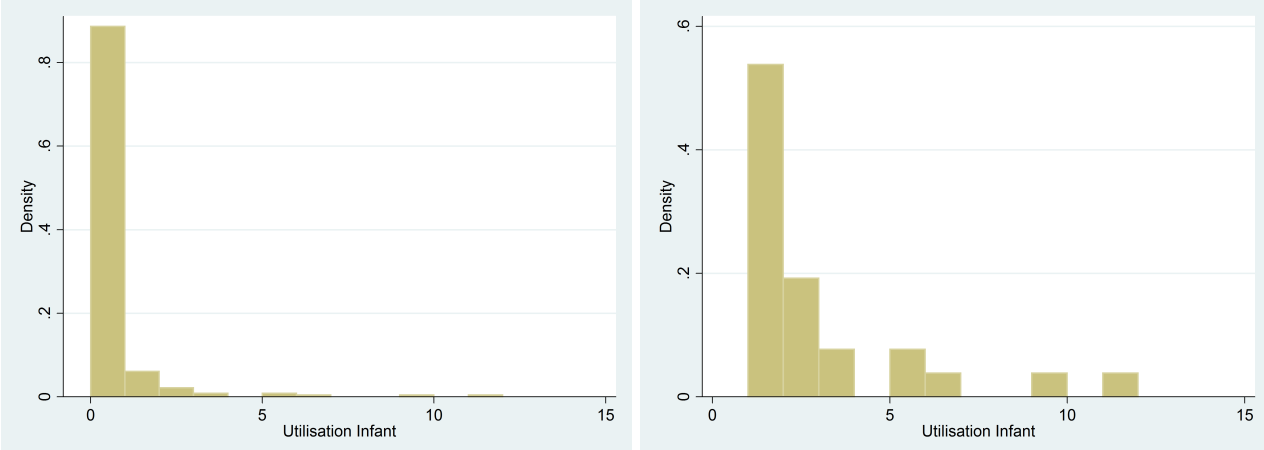

Figure 6. Histograms of Utilisation. Number of Visits, left panel includes zero visits and right panel excludes them. 

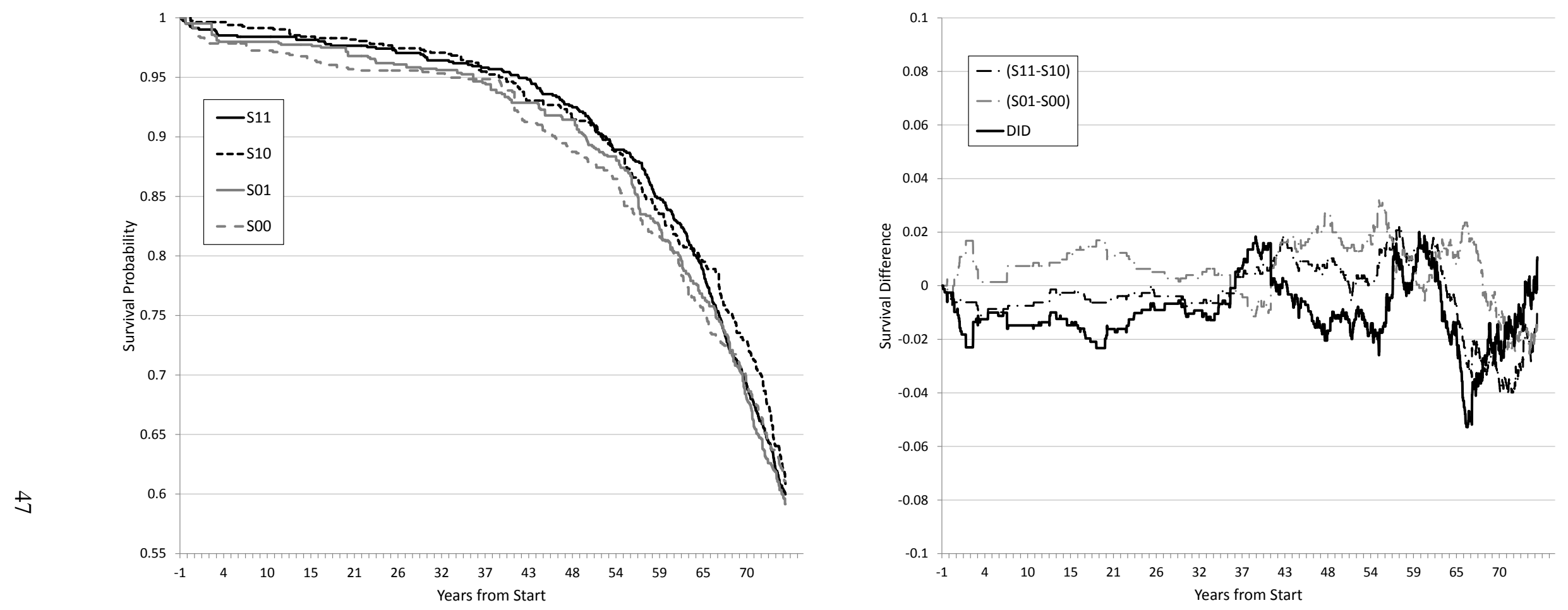

Figure 7. Survival Curves for Children Born Before the Intervention. (Also see Table C.15). The left figure plots survival curves for sub-groups of children as follows. Black curves refer to children born in treated areas and grey curves to children born in control areas. Solid curves refer to children with younger siblings born in the eligible period and dashed curves refer to children without younger siblings born in the eligible period. The $x$ axis measures time in years with reference to the start of sibling eligibility: if the sibling's conception was before 1 October 1931, the start is on that day, and otherwise at the time of the sibling's conception. The right figure shows single and double differences: when subtracting the curve $S 10$ (treated area, has no eligible sibling) from the curve $S 11$ (treated area, has eligible sibling) we get the difference in survival prospects between the two groups, and by calculating the double difference $S 11-S 10-(S 01-S 00)$, we capture the effect of sibling eligibility. 


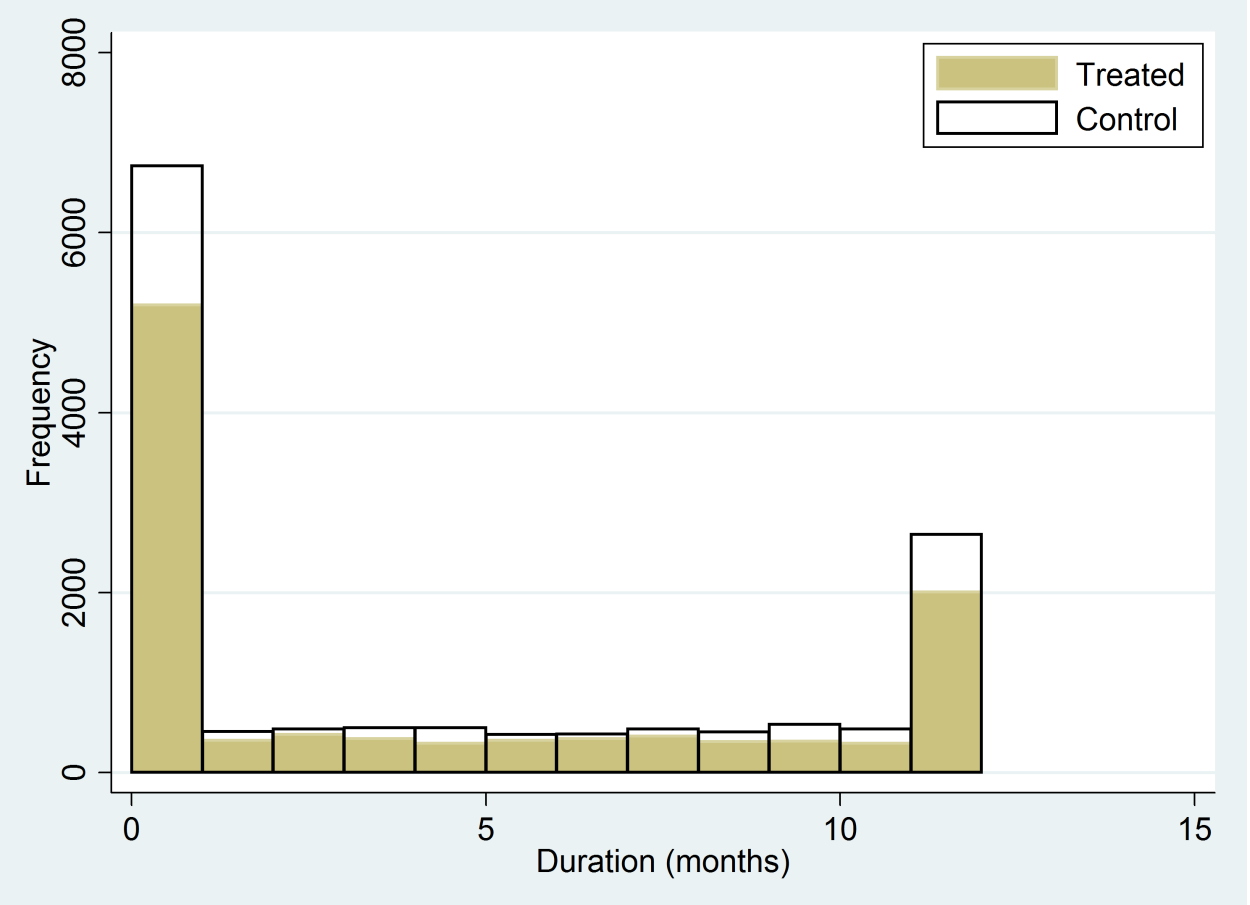

Figure 8. Histogram for eligibility in months, and the corresponding theoretical eligibility for the control group.

\section{B Tables}


Table 1. Infant and Future Survival Chances

\begin{tabular}{|c|c|c|c|c|c|c|c|c|}
\hline \multirow[b]{2}{*}{ A. All Live Births $(N=24,374)$} & \multicolumn{2}{|c|}{$d_{0-1}$} & \multicolumn{2}{|c|}{$d_{0-5}$} & \multicolumn{2}{|c|}{$d_{0-40}$} & \multicolumn{2}{|c|}{$d_{0-75}$} \\
\hline & $(1)$ & (2) & (3) & (4) & $(5)$ & $(6)$ & (7) & $(8)$ \\
\hline Treated parish $\times$ Duration of eligibility & $\begin{array}{c}-0.1414 * * \\
(0.061)\end{array}$ & $\begin{array}{c}-0.2032 * * * \\
(0.069)\end{array}$ & $\begin{array}{c}-0.0872 \\
(0.057)\end{array}$ & $\begin{array}{c}-0.1624 * * \\
(0.071)\end{array}$ & $\begin{array}{c}-0.1295^{*} \\
(0.076)\end{array}$ & $\begin{array}{c}-0.1986 * * \\
(0.098)\end{array}$ & $\begin{array}{c}-0.2972 * * \\
(0.143)\end{array}$ & $\begin{array}{c}-0.3328 * * \\
(0.157)\end{array}$ \\
\hline AITT & -1.0889 & -1.5653 & -0.6716 & -1.2512 & -0.9979 & -1.5295 & -2.2891 & -2.5639 \\
\hline Pre-Mean & 6.617 & 6.617 & 8.257 & 8.257 & 11.221 & 11.221 & 36.535 & 36.535 \\
\hline B. Repeat Mothers Pooled $(N=11,406)$ & (1) & (2) & (3) & (4) & (5) & $(6)$ & (7) & (8) \\
\hline Treated parish $\times$ Duration of eligibility & $\begin{array}{c}-0.2776^{* * *} \\
(0.099)\end{array}$ & $\begin{array}{c}-0.3420 * * * \\
(0.119)\end{array}$ & $\begin{array}{c}-0.1684 * \\
(0.097)\end{array}$ & $\begin{array}{c}-0.2668 * \\
(0.139)\end{array}$ & $\begin{array}{c}-0.2059 \\
(0.129)\end{array}$ & $\begin{array}{c}-0.2935 * * \\
(0.141)\end{array}$ & $\begin{array}{c}-0.3450 * \\
(0.184)\end{array}$ & $\begin{array}{c}-0.4638 * * \\
(0.217)\end{array}$ \\
\hline AITT & -2.1386 & -2.6341 & -1.2969 & -2.0551 & -1.5860 & -2.2608 & -2.6575 & -3.5730 \\
\hline Pre-Mean & 6.612 & 6.612 & 8.251 & 8.251 & 11.223 & 11.223 & 36.491 & 36.491 \\
\hline C. Mother Fixed Effects $(N=11,406)$ & $(1)$ & $(2)$ & (3) & (4) & $(5)$ & $(6)$ & $(7)$ & $(8)$ \\
\hline Treated parish $\times$ Duration of eligibility & $\begin{array}{c}-0.3759 * * * \\
(0.113)\end{array}$ & $\begin{array}{c}-0.4880^{* * *} \\
(0.145)\end{array}$ & $\begin{array}{c}-0.2756^{* *} \\
(0.113)\end{array}$ & $\begin{array}{c}-0.4520^{* * *} \\
(0.148)\end{array}$ & $\begin{array}{c}-0.3052 * * \\
(0.147)\end{array}$ & $\begin{array}{c}-0.4564 * * * \\
(0.164)\end{array}$ & $\begin{array}{c}-0.4382 * * \\
(0.196)\end{array}$ & $\begin{array}{c}-0.6581 * * * \\
(0.251)\end{array}$ \\
\hline AITT & -2.8956 & -3.7593 & -2.1230 & -3.4818 & -2.3508 & -3.5157 & -3.3757 & -5.0691 \\
\hline Pre-Mean & 6.612 & 6.612 & 8.251 & 8.251 & 11.223 & 11.223 & 36.491 & 36.491 \\
\hline
\end{tabular}

Standard errors clustered at the parish level in parenthesis. Treated Parish $\times$ Duration of Eligibility denotes the DID term for exposure to the infant program. $d_{0-x}$ denotes mortality before age $x$. Each specification includes the number of months of eligibility for each of the interventions and quarter-of-birth dummies for each of the 20 quarters ( $Q O B$ Effects). The odd-numbered columns present the basic DID specification in which the controls are a treatment-district dummy, quarter $\times$ year of birth dummies, as well as an indicator for exposure to the antenatal care intervention (which is an interaction of treated district with duration of eligibility for the antenatal program). The even-numbered columns include a richer set of controls including covariates, parish fixed effects and parish specific trends. AITT is the intent-to-treat effect for the average eligible individual (i.e. the product of the DID point estimates and the average eligibility period conditional on enrollment). Pre-Mean represents the mortality rate for children born before the start of the eligibility period (starting 2 October 1930). Variable definitions and sources are provided in Appendix 
Table 2. Characteristics of Matched and Control Districts

\begin{tabular}{lcccccc}
\hline & $\begin{array}{c}\text { All } \\
(1)\end{array}$ & $\begin{array}{c}\text { Treated } \\
(2)\end{array}$ & $\begin{array}{c}\text { Other } \\
(3)\end{array}$ & $\begin{array}{c}\text { Std. Dif. } \\
(2) \text { vs. (3) }\end{array}$ & $\begin{array}{c}\text { Matched } \\
(5)\end{array}$ & $\begin{array}{c}\text { Std. Dif. } \\
(2) \text { vs. (5) }\end{array}$ \\
\hline A. Matching Characteristics from the $\mathbf{1 9 3 0}$ Census. & & & & \\
\hline Agriculture & 0.340 & 0.324 & 0.340 & -0.040 & 0.302 & 0.054 \\
Manufacturing & 0.318 & 0.340 & 0.318 & 0.096 & 0.345 & -0.018 \\
Fertile Women & 0.121 & 0.101 & 0.121 & -0.135 & 0.100 & 0.060 \\
Income & 811 & 839 & 810 & 0.042 & 847 & -0.013 \\
Wealth & 2,525 & 2,703 & 2,521 & 0.080 & 2,655 & 0.022 \\
Urban & 0.334 & 0.439 & 0.331 & 0.158 & 0.437 & 0.003 \\
\hline Population & $6,271,266$ & 258,418 & $6,004,052$ & & 160,987 &
\end{tabular}

\section{B. Vital Statistics and SES of 1930 Births.}

\begin{tabular}{|c|c|c|c|c|c|c|}
\hline Live Birth & 0.973 & 0.974 & & & 0.979 & -0.024 \\
\hline Wedlock & 0.836 & 0.888 & & & 0.884 & 0.008 \\
\hline Infant Mortality & 0.055 & 0.063 & & & 0.064 & -0.002 \\
\hline Perinatal Mortality & $0.030^{*}$ & 0.017 & & & 0.021 & -0.017 \\
\hline Infectious Disease & $0.005^{*}$ & 0.005 & & & 0.006 & -0.004 \\
\hline Other Causes & $0.020^{*}$ & 0.041 & & & 0.038 & 0.011 \\
\hline Maternal Mortality & 348.1 & 417.275 & & & 381.785 & 0.004 \\
\hline Mother's Age & 29.45 & 29.455 & & & 29.610 & -0.017 \\
\hline Professional, technical & & 0.049 & & & 0.038 & 0.037 \\
\hline Administrative, managerial & & 0.025 & & & 0.016 & 0.046 \\
\hline Clerical & & 0.016 & & & 0.025 & -0.045 \\
\hline Sales worker & & 0.029 & & & 0.023 & 0.031 \\
\hline Service worker & & 0.022 & & & 0.010 & 0.071 \\
\hline Agricultural & & 0.297 & & & 0.307 & -0.015 \\
\hline Production worker & & 0.426 & & & 0.460 & -0.048 \\
\hline \multicolumn{7}{|c|}{ C. Other Institutional Variables. } \\
\hline Institutional Delivery & 0.242 & 0.335 & 0.239 & 0.151 & 0.273 & 0.096 \\
\hline Weeks Compulsory Schooling & 226.2 & 223.8 & 226.3 & -0.244 & 223.7 & 0.012 \\
\hline Seven Years Compulsory & 0.606 & 0.838 & 0.598 & 0.392 & 0.666 & 0.287 \\
\hline Secondary Enrolment & - & 0.201 & - & - & 0.205 & -0.007 \\
\hline
\end{tabular}

Panel A contains local characteristics from the 1930 census, which were used to match treated parishes to control parishes. Panel B contains characteristics of 1930 births (which were not available in the 1930 census). Whenever possible, these characteristics are compared with the national averages; however * signifies that national and local statistics not directly comparable. Panel $C$ contains information on other contextual variables relevant to the cohorts included. 'Std Dif.' presents the standardised difference (cf. Imbens and Wooldridge, 2009); a standardised difference of less than 0.25 is generally viewed as acceptable. 
Table 3. Placebo Estimates for the 1940-44 Cohorts

\begin{tabular}{|c|c|c|c|c|c|c|c|c|}
\hline \multirow[b]{2}{*}{ All Live Births $(N=21,795)$} & \multicolumn{2}{|c|}{$d_{0-1}$} & \multicolumn{2}{|c|}{$d_{0-5}$} & \multicolumn{2}{|c|}{$d_{0-40}$} & \multicolumn{2}{|c|}{$d_{0-69}$} \\
\hline & (1) & (2) & (3) & (4) & $(5)$ & (6) & (7) & $(8)$ \\
\hline Treated parish $\times$ Duration of eligibility & -0.0335 & -0.0333 & -0.0335 & -0.0356 & -0.0256 & -0.0390 & 0.0002 & -0.0291 \\
\hline & $(0.062)$ & $(0.059)$ & $(0.078)$ & $(0.076)$ & $(0.085)$ & $(0.082)$ & $(0.150)$ & $(0.148)$ \\
\hline AITT & -0.2550 & -0.2532 & -0.2553 & -0.2709 & -0.1948 & -0.2967 & 0.0019 & -0.2212 \\
\hline Pre-Mean & 5.995 & 5.995 & 7.832 & 7.832 & 10.383 & 10.383 & 22.908 & 22.908 \\
\hline
\end{tabular}

Standard errors clustered at the parish level in parenthesis. Treated Parish $\times$ Duration of Eligibility denotes the DID term for placebo exposure to the infant program; assuming it was implemented ten years later in the same areas. All other definitions are equivalent to those in Table 1 , with the exception that the odd-numbered columns only control for female sex in addition to the various fixed effects and parish-specific trends. 
Table 4. Selection and Confounders

\begin{tabular}{|c|c|c|c|c|c|c|c|c|c|c|}
\hline \multirow[t]{2}{*}{ PANEL A } & \multicolumn{2}{|c|}{ Mother's Age } & \multicolumn{2}{|c|}{ Wedlock } & \multicolumn{2}{|c|}{ SES Agriculture } & \multicolumn{2}{|c|}{ SES Manufacturing } & \multicolumn{2}{|c|}{ Has Younger Sibling } \\
\hline & (1) & (2) & (3) & (4) & (5) & (6) & (7) & (8) & (9) & $(10)$ \\
\hline \multirow[t]{2}{*}{ Treated parish $\times$ Cohort exposed to announcement } & -0.0408 & & -0.0081 & & 0.0041 & & 0.0285 & & -0.0121 & \\
\hline & $(0.213)$ & & $(0.012)$ & & $(0.030)$ & & $(0.021)$ & & $(0.024)$ & \\
\hline \multirow[t]{2}{*}{ Treated parish $\times$ Cohort born after end of programme } & -0.0339 & & 0.0016 & & 0.0299 & & 0.0162 & & -0.0229 & \\
\hline & $(0.229)$ & & $(0.008)$ & & $(0.035)$ & & $(0.025)$ & & $(0.049)$ & \\
\hline \multirow[t]{2}{*}{ Treated parish $\times$ Duration of eligibility } & & 0.0093 & & $-0.0022 * *$ & & -0.0009 & & 0.0008 & & 0.0009 \\
\hline & & $(0.018)$ & & $(0.001)$ & & $(0.002)$ & & $(0.002)$ & & $(0.002)$ \\
\hline Pre-Mean & 29.576 & 29.576 & 0.881 & 0.881 & 0.280 & 0.280 & 0.452 & 0.452 & 0.432 & 0.432 \\
\hline $\mathrm{N}$ & 25,029 & 25,029 & 25,029 & 25,029 & 25,029 & 25,029 & 25,029 & 25,029 & 25,029 & 25,029 \\
\hline \multirow[t]{2}{*}{ PANEL B } & \multicolumn{2}{|c|}{ Birth Rate } & \multicolumn{2}{|c|}{ Midwife Share } & \multicolumn{2}{|c|}{ Hospital Birth } & \multicolumn{2}{|c|}{ School Year Length } & \multicolumn{2}{|c|}{ Comp Schooling 7Y } \\
\hline & (1) & (2) & (3) & (4) & (5) & (6) & (7) & $(8)$ & (9) & (10) \\
\hline Treated parish $\times$ Cohort exposed to announcement & $\begin{array}{l}-0.2041 \\
(0.161)\end{array}$ & & $\begin{array}{l}1.9853 \\
(3.064)\end{array}$ & & $\begin{array}{l}-0.0002 \\
(0.013)\end{array}$ & & $\begin{array}{l}-0.1684 \\
(1.219)\end{array}$ & & $\begin{array}{l}-0.0866 \\
(0.058)\end{array}$ & \\
\hline Treated parish $\times$ Cohort born after end of programme & $\begin{array}{l}-0.1907 \\
(0.182)\end{array}$ & & $\begin{array}{l}2.9423 \\
(3.320)\end{array}$ & & $\begin{array}{c}-0.0392^{* *} \\
(0.017)\end{array}$ & & $\begin{array}{l}-0.1625 \\
(1.655)\end{array}$ & & $\begin{array}{c}-0.0866 \\
(0.072)\end{array}$ & \\
\hline Treated parish $\times$ Duration of eligibility & & $\begin{array}{l}0.0116 \\
(0.015)\end{array}$ & & $\begin{array}{l}0.2061 \\
(0.258)\end{array}$ & & $\begin{array}{l}-0.0019 \\
(0.002)\end{array}$ & & $\begin{array}{l}-0.0041 \\
(0.089)\end{array}$ & & $\begin{array}{l}0.0034 \\
(0.003)\end{array}$ \\
\hline Pre-Mean & 4.982 & 4.982 & 67.836 & 67.836 & 0.310 & 0.310 & 223.723 & 223.723 & 0.753 & 0.753 \\
\hline $\mathrm{N}$ & 2,360 & 2,360 & 235 & 235 & 25,029 & 25,029 & 25,029 & 25,029 & 25,029 & 25,029 \\
\hline
\end{tabular}

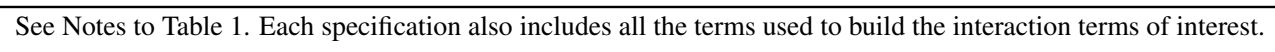


Table 5. Effect Heterogeneity

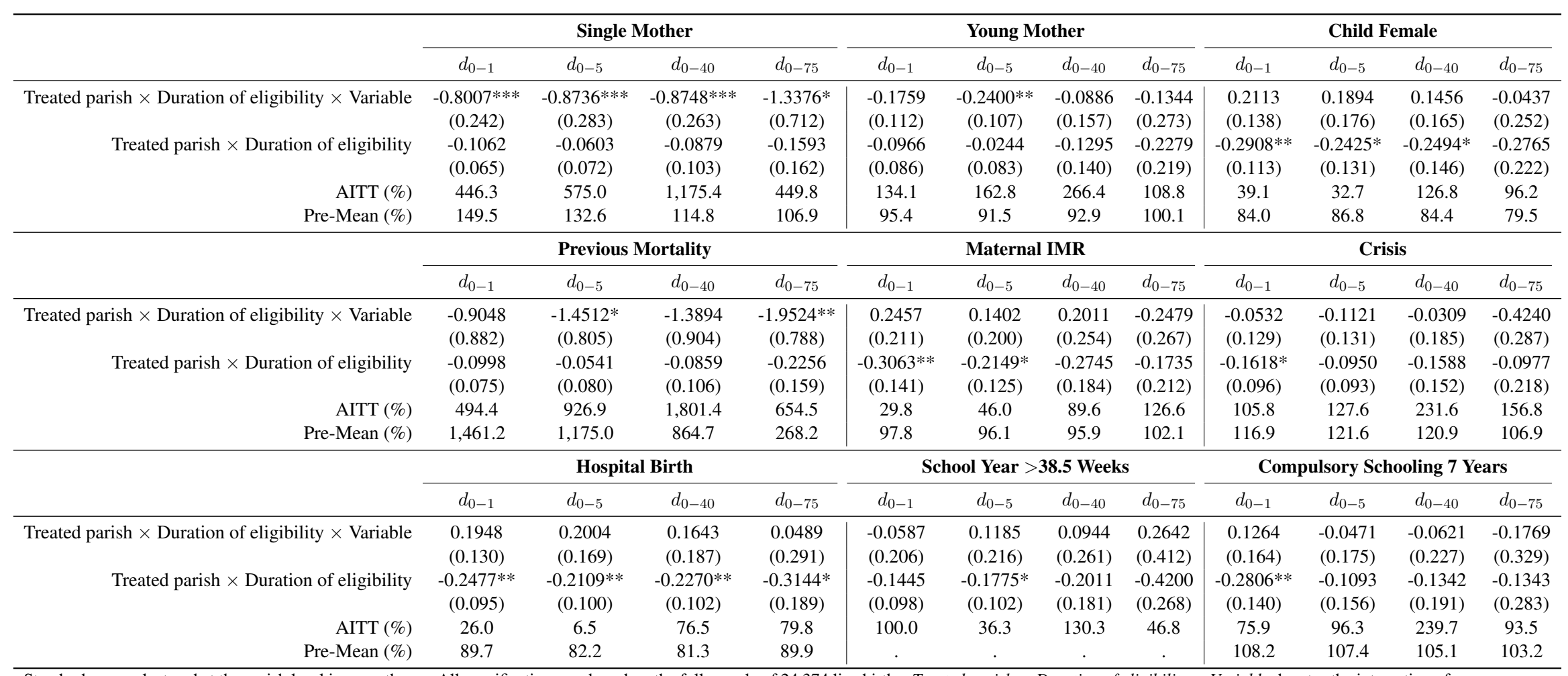

Standard errors clustered at the parish level in parentheses. All specifications are based on the full sample of 24,374 live births. Treated parish $\times$ Duration of eligibility $\times$ Variable denotes the interaction of the original DID variable with the variable in the column heading. AITT (\%) represents the relative size of the estimated intent-to-treat effect in the subgroup defined by the interaction variable, compare to the estimated effect in the entire sample (results given in Table 1). Pre-Mean (\%) denotes the level of pre-intervention mortality rate for the corresponding group compared to the pre-treatment level in the entire sample. Previous Mortality is a dummy variable which takes on the value one if the mother had a child in the pre-intervention period which died before their first birthday. Maternal IMR is a dummy variable which takes on the value one if the infant mortality rate in the mother's birth parish was above the median for her birth year. Each specification includes the richer set of controls including covariates, parish fixed effects and parish specific trends. Variable definitions and sources are provided in Appendix A. Also see notes to Table 1. 
Table 6. Utilisation

\begin{tabular}{|c|c|c|c|c|}
\hline & \multirow{2}{*}{$\begin{array}{c}\text { Enrolment (LPM) } \\
\text { Eligible } \\
(1)\end{array}$} & \multicolumn{3}{|c|}{ Utilisation (OLS) } \\
\hline & & $\begin{array}{l}\text { Eligible } \\
\text { (2) }\end{array}$ & $\begin{array}{l}\text { Enrolled } \\
\text { (3) }\end{array}$ & $\begin{array}{l}\text { All } \\
\text { (4) }\end{array}$ \\
\hline Eligibility (months) & $\begin{array}{c}0.0459 * * * \\
(0.004)\end{array}$ & $\begin{array}{c}0.2877 * * * \\
(0.096)\end{array}$ & $\begin{array}{l}0.2718^{*} \\
(0.138)\end{array}$ & $\begin{array}{c}0.2498^{* * *} \\
(0.071)\end{array}$ \\
\hline Female & $\begin{array}{l}0.0037 \\
(0.017)\end{array}$ & $\begin{array}{l}0.2333 \\
(0.186)\end{array}$ & $\begin{array}{l}0.3999 \\
(0.275)\end{array}$ & $\begin{array}{l}0.0571 \\
(0.051)\end{array}$ \\
\hline Twin & $\begin{array}{l}0.0783 \\
(0.074)\end{array}$ & $\begin{array}{l}0.1299 \\
(0.414)\end{array}$ & $\begin{array}{l}-0.2508 \\
(0.644)\end{array}$ & $\begin{array}{l}0.0165 \\
(0.102)\end{array}$ \\
\hline Wedlock & $\begin{array}{l}-0.0132 \\
(0.029)\end{array}$ & $\begin{array}{l}0.4387 \\
(0.446)\end{array}$ & $\begin{array}{l}0.9733 \\
(0.812)\end{array}$ & $\begin{array}{l}0.1501 \\
(0.167)\end{array}$ \\
\hline Young mother & $\begin{array}{l}-0.0089 \\
(0.023)\end{array}$ & $\begin{array}{l}0.0620 \\
(0.108)\end{array}$ & $\begin{array}{l}0.1441 \\
(0.224)\end{array}$ & $\begin{array}{l}0.0142 \\
(0.030)\end{array}$ \\
\hline Old mother & $\begin{array}{l}-0.0370 \\
(0.022)\end{array}$ & $\begin{array}{l}-0.0214 \\
(0.136)\end{array}$ & $\begin{array}{l}0.1233 \\
(0.178)\end{array}$ & $\begin{array}{l}-0.0144 \\
(0.036)\end{array}$ \\
\hline High socio-ecomomic status & $\begin{array}{l}0.0103 \\
(0.031)\end{array}$ & $\begin{array}{l}0.1356 \\
(0.188)\end{array}$ & $\begin{array}{l}0.2060 \\
(0.273)\end{array}$ & $\begin{array}{l}0.0267 \\
(0.054)\end{array}$ \\
\hline Low socio-ecomomic status & $\begin{array}{l}-0.0731 \\
(0.066)\end{array}$ & $\begin{array}{l}-0.0087 \\
(0.415)\end{array}$ & $\begin{array}{l}0.4871 \\
(0.521)\end{array}$ & $\begin{array}{l}-0.0004 \\
(0.097)\end{array}$ \\
\hline IMR in mother's birth year & $\begin{array}{l}-0.2198 \\
(0.260)\end{array}$ & $\begin{array}{l}1.3616 \\
(2.443)\end{array}$ & $\begin{array}{l}5.8047 \\
(4.320)\end{array}$ & $\begin{array}{l}0.4164 \\
(0.756)\end{array}$ \\
\hline Crisis area & $\begin{array}{c}-0.2800 * \\
(0.161)\end{array}$ & $\begin{array}{l}-3.8805 \\
(3.932)\end{array}$ & $\begin{array}{l}-5.5739 \\
(6.289)\end{array}$ & $\begin{array}{l}-0.9284 \\
(0.871)\end{array}$ \\
\hline Child born in hospital & $\begin{array}{l}-0.0646 \\
(0.041)\end{array}$ & $\begin{array}{l}0.2381 \\
(0.493)\end{array}$ & $\begin{array}{l}1.0466 \\
(0.780)\end{array}$ & $\begin{array}{l}0.0925 \\
(0.170)\end{array}$ \\
\hline$N$ & 2,574 & 2,574 & 1,212 & 9,792 \\
\hline $\begin{array}{l}\text { Standard errors clustered } \\
\text { and (2) include eligible in } \\
\text { parish at a date which imp } \\
\text { only children who also er } \\
\text { for which births from oth } \\
\text { included. Variable definiti }\end{array}$ & $\begin{array}{l}\text { the parish level in } \\
\text { viduals - i.e. chil } \\
\text { ed eligibility for th } \\
\text { lled. The fourth }\end{array}$ & $\begin{array}{l}\text { parenthesis } \\
\text { ren who we } \\
\text { services. C } \\
\text { olumn is a }\end{array}$ & lumn (3) & $\begin{array}{l}\text { ons (1) } \\
\text { treated } \\
\text { ncludes } \\
\text { stimate, } \\
\text { are also }\end{array}$ \\
\hline
\end{tabular}


Table 7. Two-Stage Least Squares Estimates

\begin{tabular}{|c|c|c|c|c|c|c|c|c|}
\hline \multirow{2}{*}{ A. SECOND STAGE } & \multicolumn{2}{|c|}{$d_{0-1}$} & \multicolumn{2}{|c|}{$d_{0-5}$} & \multicolumn{2}{|c|}{$d_{0-40}$} & \multicolumn{2}{|c|}{$d_{0-75}$} \\
\hline & (1) & (2) & (3) & (4) & (5) & (6) & (7) & (8) \\
\hline Enrolment infant & $\begin{array}{c}-6.6642 * * * \\
(2.255)\end{array}$ & & $\begin{array}{l}-3.6026 \\
(2.377)\end{array}$ & & $\begin{array}{c}-5.6847 * * \\
(2.315)\end{array}$ & & $\begin{array}{c}-8.3706^{*} \\
(5.054)\end{array}$ & \\
\hline Utilisation infant & & $\begin{array}{c}-1.1422 * * * \\
(0.415)\end{array}$ & & $\begin{array}{l}-0.6403 \\
(0.446)\end{array}$ & & $\begin{array}{c}-1.0583^{*} \\
(0.607)\end{array}$ & & $\begin{array}{l}-1.6628 \\
(1.121)\end{array}$ \\
\hline Pre-Mean & 6.617 & 6.617 & 8.257 & 8.257 & 11.221 & 11.221 & 36.535 & 36.535 \\
\hline
\end{tabular}

B. First STAGE

Infant

\begin{tabular}{lcc} 
& Enrollment & Utilization \\
\hline Treated parish $\times$ Duration of eligibility & $0.0459 * * *$ & $0.2514 * * *$ \\
& $(0.004)$ & $(0.090)$ \\
Eligible infant & 0.0495 & $-0.3627^{* *}$ \\
& $(0.084)$ & $(0.148)$ \\
$F$ test, excluded instruments & 137.1 & 46.9 \\
$p$ Value & 0.000 & 0.000 \\
Angrist-Pischke $F$ test & 293.8 & 456.7 \\
$p$ Value & 0.000 & 0.000
\end{tabular}

Standard errors clustered at the parish level in parenthesis. Enrolment Infant is a dummy and Utilisation Infant is a count variable capturing the number of visits during infancy including zero visits. All specifications are based on the utilisation sample of 9,792 live births and include the

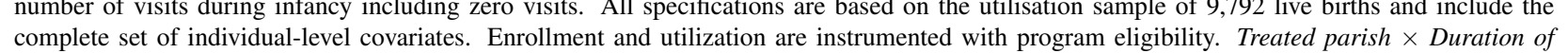
complete set of individual-level covariates. Enrollment and utilization are instrumented with program eligibility. Treated parish $\times$ Duration of
eligibility represents the length of the eligibility period in months. In addition to the standard $F$ test for excluded instruments, we provide the corresponding statistics for Angrist and Pischke's test for weak identification (cf. Angrist and Pischke, 2008. 
Table 8. Childhood Results by Death Cause

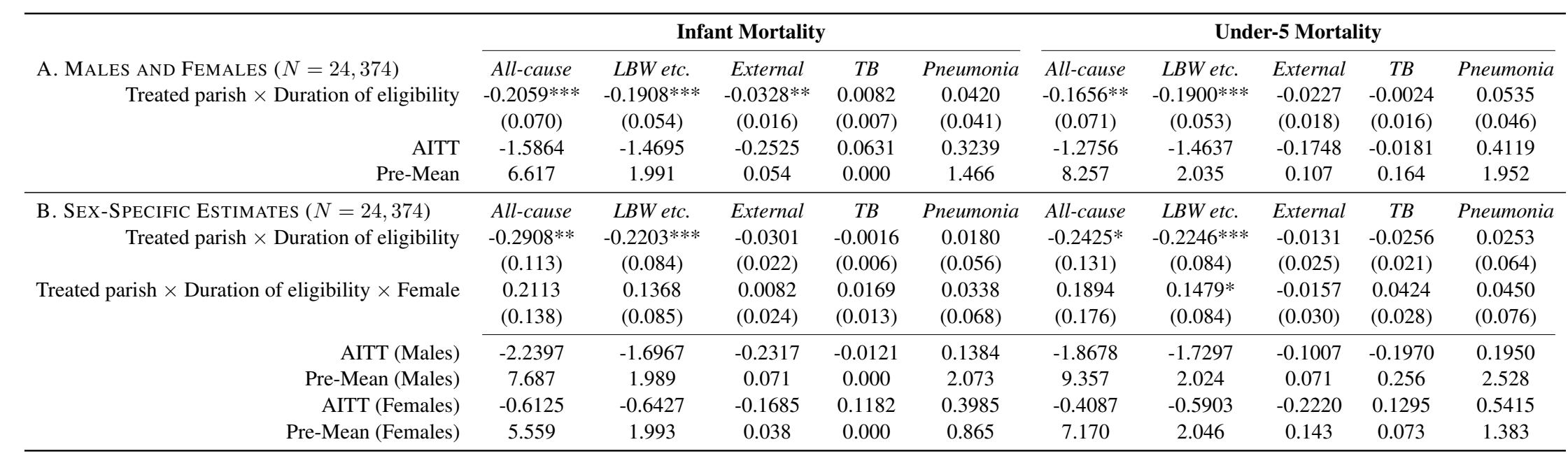


Table 9. Adult Results by Death Cause

\begin{tabular}{|c|c|c|c|c|c|c|c|c|c|c|}
\hline \multicolumn{11}{|c|}{ A. Mortality Between AgES $50-75(N=21,150)$} \\
\hline \multirow{3}{*}{ Treated parish $\times$ Duration of eligibility } & All-cause & Resp & Digestive & Infect & Nervous & External & Cancer & Cardio & Symptoms & All Other \\
\hline & $-0.3500 * *$ & 0.0247 & 0.0116 & $-0.0434 *$ & $-0.0487 *$ & 0.0340 & $-0.2854 * *$ & -0.0924 & -0.0351 & 0.0847 \\
\hline & $(0.136)$ & $(0.056)$ & $(0.034)$ & $(0.023)$ & $(0.028)$ & $(0.044)$ & $(0.134)$ & $(0.090)$ & $(0.044)$ & $(0.068)$ \\
\hline AITT & -2.6960 & 0.1900 & 0.0897 & -0.3340 & -0.3754 & 0.2622 & -2.1987 & -0.7117 & -0.2707 & 0.6525 \\
\hline Pre-Mean & 26.249 & 1.811 & 1.015 & 0.210 & 0.391 & 1.579 & 7.373 & 7.778 & 2.105 & 3.987 \\
\hline Average age at death & 65.518 & 67.321 & 64.594 & 68.776 & 66.343 & 61.147 & 65.428 & 65.459 & 68.573 & 64.940 \\
\hline \multicolumn{11}{|c|}{ B. Mortality Between ages $50-75$, By Sex $(N=21,150)$} \\
\hline \multirow{3}{*}{ Treated parish $\times$ Duration of eligibility } & All-cause & Resp & Digestive & Infect & Nervous & External & Cancer & Cardio & Symptoms & All Other \\
\hline & -0.3558 & 0.0903 & 0.0045 & $-0.0839 *$ & -0.0222 & -0.0316 & -0.1151 & $-0.2495 *$ & -0.0228 & 0.0746 \\
\hline & $(0.234)$ & $(0.081)$ & $(0.047)$ & $(0.048)$ & $(0.026)$ & $(0.054)$ & $(0.137)$ & $(0.136)$ & $(0.068)$ & $(0.120)$ \\
\hline \multirow[t]{2}{*}{ Treated parish $\times$ Female $\times$ Duration of eligibility } & 0.0147 & $-0.1283^{*}$ & 0.0143 & 0.0769 & -0.0505 & 0.1297 & $-0.3337 * *$ & $0.3066^{*}$ & -0.0223 & 0.0219 \\
\hline & $(0.262)$ & $(0.074)$ & $(0.056)$ & $(0.061)$ & $(0.047)$ & $(0.099)$ & $(0.161)$ & $(0.156)$ & $(0.098)$ & $(0.139)$ \\
\hline AITT (Males) & -2.7404 & 0.6955 & 0.0350 & -0.6465 & -0.1713 & -0.2437 & -0.8868 & -1.9216 & -0.1753 & 0.5743 \\
\hline Pre-Mean (Males) & 33.002 & 2.315 & 0.920 & 0.141 & 0.460 & 1.947 & 7.464 & 11.975 & 2.679 & 5.101 \\
\hline AITT (Females) & -2.6272 & -0.2925 & 0.1451 & -0.0540 & -0.5604 & 0.7554 & -3.4574 & 0.4403 & -0.3472 & 0.7434 \\
\hline Pre-Mean (Females) & 19.979 & 1.343 & 1.102 & 0.275 & 0.327 & 1.237 & 7.289 & 3.881 & 1.572 & 2.953 \\
\hline Average age at death (Males) & 65.215 & 67.311 & 64.290 & 69.649 & 66.490 & 60.239 & 65.677 & 65.201 & 68.898 & 63.793 \\
\hline Average age at death (Females) & 65.982 & 67.337 & 65.014 & 67.834 & 66.176 & 62.921 & 65.185 & 66.145 & 68.225 & 66.932 \\
\hline
\end{tabular}

\begin{tabular}{|c|c|c|c|c|c|c|c|c|c|c|}
\hline \multicolumn{11}{|c|}{ C. Mortality between Ages $50-75$ Disaggregated $(N=21,150)$} \\
\hline & \multicolumn{5}{|c|}{ Cancers } & \multicolumn{2}{|c|}{ Infections } & \multicolumn{3}{|c|}{ Cardiovascular } \\
\hline \multirow{3}{*}{ Treated parish $\times$ Duration of eligibility } & Lung & Upper GI & Lower GI & Genital & Other & Septicemia & Other & $A M I$ & Arrest & Other \\
\hline & -0.0282 & 0.0300 & -0.1930 & -0.0166 & -0.0777 & -0.0154 & $-0.0256^{*}$ & -0.0697 & 0.0475 & -0.0692 \\
\hline & $(0.032)$ & $(0.030)$ & $(0.134)$ & $(0.054)$ & $(0.058)$ & $(0.021)$ & $(0.015)$ & $(0.059)$ & $(0.041)$ & $(0.065)$ \\
\hline AITT & -0.2169 & 0.2314 & -1.4869 & -0.1276 & -0.5986 & -0.1189 & -0.1969 & -0.5369 & 0.3659 & -0.5328 \\
\hline Pre-Mean & 1.289 & 0.552 & 1.602 & 1.688 & 2.243 & 0.174 & 0.043 & 3.236 & 0.901 & 3.641 \\
\hline
\end{tabular}

Estimates are based on official death cause statistics, available from 1952 onwards - and the groups have been constructed in accordance with ICD-10 categories. Panel A shows overall

effects, Panel B shows results by sex. Panel C shows a finer breakdown of some of the most important death cause groups. 
Table 10. Secondary Schooling Enrolment

\begin{tabular}{rcccccccc}
\hline & \multicolumn{2}{l}{ MALES AND FEMALES } & & \multicolumn{2}{c}{ MALES } & & \multicolumn{2}{c}{ FEMALES } \\
\cline { 2 - 3 } Treated parish $\times$ Duration of eligibility & -0.0006 & 0.0005 & & -0.0038 & -0.0017 & & 0.0026 & $0.0034^{*}$ \\
& $(0.002)$ & $(0.002)$ & & $(0.003)$ & $(0.002)$ & & $(0.002)$ & $(0.002)$ \\
AITT & -0.0043 & 0.0037 & & -0.0289 & -0.0135 & & 0.0204 & 0.0264 \\
Pre-Mean & 0.203 & 0.203 & & 0.186 & 0.186 & & 0.220 & 0.220 \\
$N$ & 22,434 & 22,434 & & 11,409 & 11,409 & & 11,025 & 11,025 \\
\hline
\end{tabular}

Standard errors clustered at the parish level in parenthesis. The dependent variable is a dummy taking on the value one if the individual enrolled in secondary schooling. 
C Appendix Tables 
Table C.11. Mothers and Children Enrolled in the Test Programme.

\begin{tabular}{lrrr}
\hline & \multicolumn{3}{c}{ Infant Care } \\
\cline { 2 - 4 } District & Enrolled & Eligible & Ratio \\
\hline Harads & 225 & 269 & .84 \\
Hälsingborg & 646 & 2025 & .32 \\
Jokkmokk & 227 & 298 & .76 \\
Lidköping & 550 & 1060 & .52 \\
Mörtfors & 363 & 445 & .82 \\
Pajala & 344 & 552 & .62 \\
Råneå & 230 & 369 & .62 \\
\hline
\end{tabular}

Table C.12. Descriptive Statistics, District Level.

\begin{tabular}{lrrrrr}
\hline Variable Name & Mean & Std. Dev. & Min & Max & $N$ \\
\hline Birthrate & 5.34 & 2.82 & 0.65 & 23.83 & 2,127 \\
Midwife Share & 69.81 & 20.96 & 15.28 & 100.00 & 240 \\
Complications & 2.31 & 2.01 & 0.00 & 8.71 & 240 \\
\hline Variable definitions and sources are provided in Appendix & A &
\end{tabular}


Table C.13. Descriptive Statistics for the Main Sample.

\begin{tabular}{|c|c|c|c|c|c|}
\hline Variable & Mean & Std. Dev. & Min & Max & $N$ \\
\hline \multicolumn{6}{|l|}{ MORTALITY. } \\
\hline Infant Mortality $\left(d_{0-1}\right)$ & 5.821 & 23.41 & 0.00 & 100.00 & 24,374 \\
\hline Child Mortality $\left(d_{0-5}\right)$ & 7.343 & 26.08 & 0.00 & 100.00 & 24,374 \\
\hline Under-40 Mortality $\left(d_{0-40}\right)$ & 10.536 & 30.70 & 0.00 & 100.00 & 24,374 \\
\hline Under-75 Mortality $\left(d_{0-75}\right)$ & 34.661 & 47.59 & 0.00 & 100.00 & 24,374 \\
\hline \multicolumn{6}{|l|}{ Childhood DeATH CAUSES. } \\
\hline Low Birth Weight etc & 2.157 & 14.53 & 0.00 & 100.00 & 24,374 \\
\hline External etc & 0.208 & 4.55 & 0.00 & 100.00 & 24,374 \\
\hline Tuberculosis & 0.208 & 4.56 & 0.00 & 100.00 & 24,374 \\
\hline Pneumonia & 1.475 & 12.05 & 0.00 & 100.00 & 24,374 \\
\hline \multicolumn{6}{|l|}{ Adult Death CAuses. } \\
\hline Respiratory disease & 1.862 & 13.52 & 0.00 & 100.00 & 21,150 \\
\hline Digestive disorders & 0.787 & 8.83 & 0.00 & 100.00 & 21,150 \\
\hline Infectious disease & 0.329 & 5.73 & 0.00 & 100.00 & 21,150 \\
\hline Diseases of the nervous system & 0.477 & 6.89 & 0.00 & 100.00 & 21,150 \\
\hline External causes & 1.492 & 12.12 & 0.00 & 100.00 & 21,150 \\
\hline Cancers & 7.420 & 26.21 & 0.00 & 100.00 & 21,150 \\
\hline Cardiovascular disease & 6.960 & 25.45 & 0.00 & 100.00 & 21,150 \\
\hline Symptoms not classified & 2.046 & 14.16 & 0.00 & 100.00 & 21,150 \\
\hline \multicolumn{6}{|l|}{ BIRTH CHARACTERISTICS. } \\
\hline Stillbirth & 2.509 & 15.64 & 0.00 & 100.00 & 25,029 \\
\hline Female & 0.487 & 0.50 & 0.00 & 1.00 & 25,029 \\
\hline Twin & 0.031 & 0.17 & 0.00 & 1.00 & 25,029 \\
\hline Mother's age & 29.495 & 6.57 & 13.97 & 51.36 & 25,029 \\
\hline IMR in Mother's birth year & -0.001 & 0.02 & -0.16 & 0.33 & 25,029 \\
\hline YOB 1930 & 0.210 & 0.41 & 0.00 & 1.00 & 25,029 \\
\hline YOB 1931 & 0.206 & 0.40 & 0.00 & 1.00 & 25,029 \\
\hline YOB 1932 & 0.204 & 0.40 & 0.00 & 1.00 & 25,029 \\
\hline YOB 1933 & 0.189 & 0.39 & 0.00 & 1.00 & 25,029 \\
\hline YOB 1934 & 0.191 & 0.39 & 0.00 & 1.00 & 25,029 \\
\hline \multicolumn{6}{|l|}{ Socio-Economic Status. } \\
\hline Wedlock & 0.893 & 0.31 & 0.00 & 1.00 & 25,029 \\
\hline SES Professional/Technical & 0.046 & 0.21 & 0.00 & 1.00 & 25,029 \\
\hline SES Administrative/Managerial & 0.022 & 0.15 & 0.00 & 1.00 & 25,029 \\
\hline SES Clerical & 0.019 & 0.14 & 0.00 & 1.00 & 25,029 \\
\hline SES Sales & 0.030 & 0.17 & 0.00 & 1.00 & 25,029 \\
\hline SES Service & 0.017 & 0.13 & 0.00 & 1.00 & 25,029 \\
\hline SES Agricultural & 0.319 & 0.47 & 0.00 & 1.00 & 25,029 \\
\hline SES Production & 0.432 & 0.50 & 0.00 & 1.00 & 25,029 \\
\hline SES Unknown & 0.115 & 0.32 & 0.00 & 1.00 & 25,029 \\
\hline Crisis area & 0.045 & 0.19 & -0.59 & 0.61 & 25,029 \\
\hline \multicolumn{6}{|l|}{ ELIGIBILITY. } \\
\hline Treated Parish & 0.510 & 0.50 & 0.00 & 1.00 & 24,374 \\
\hline Duration of Eligibility & 4.255 & 4.81 & 0.00 & 12.00 & 24,374 \\
\hline \multicolumn{6}{|l|}{ CONTEXTUAL VARIABLES. } \\
\hline Institutional Delivery & 0.345 & 0.48 & 0.00 & 1.00 & 24,374 \\
\hline Weeks Compulsory Schooling & 228.947 & 6.64 & 207.42 & 234.00 & 24,374 \\
\hline Seven Years Compulsory & 0.781 & 0.41 & 0.00 & 1.00 & 24,374 \\
\hline Secondary Enrolment & 0.223 & 0.42 & 0.00 & 1.00 & 22,434 \\
\hline
\end{tabular}

Variable definitions and sources are provided in Appendix A. 
Table C.14. Descriptive Statistics for Different Samples.

\begin{tabular}{|c|c|c|c|c|c|c|}
\hline \multirow[b]{2}{*}{ Variable } & \multicolumn{2}{|c|}{ All } & \multicolumn{2}{|c|}{ Mother FE } & \multicolumn{2}{|c|}{ Utilization } \\
\hline & Mean & $N$ & Mean & $N$ & Mean & $N$ \\
\hline \multicolumn{7}{|l|}{ MORTALITY. } \\
\hline Infant Mortality $\left(d_{0-1}\right)$ & 5.821 & 24,374 & 7.285 & 11,406 & 5.085 & 9,793 \\
\hline Child Mortality $\left(d_{0-5}\right)$ & 7.343 & 24,374 & 9.182 & 11,406 & 6.562 & 9,793 \\
\hline Under-40 Mortality $\left(d_{0-40}\right)$ & 10.536 & 24,374 & 12.707 & 11,406 & 9.674 & 9,793 \\
\hline Under-75 Mortality $\left(d_{0-75}\right)$ & 34.661 & 24,374 & 36.744 & 11,406 & 32.939 & 9,793 \\
\hline \multicolumn{7}{|l|}{ BIRTH CHARACTERISTICS. } \\
\hline Stillbirth & 2.509 & 25,029 & 0.829 & 11,494 & 3.166 & 10,103 \\
\hline Female & 0.487 & 25,029 & 0.488 & 11,494 & 0.485 & 10,103 \\
\hline Twin & 0.031 & 25,029 & 0.063 & 11,494 & 0.032 & 10,103 \\
\hline Mother's age & 29.495 & 25,029 & 29.700 & 11,494 & 29.939 & 10,103 \\
\hline IMR in Mother's birth year & -0.001 & 25,029 & -0.000 & 11,494 & -0.003 & 10,103 \\
\hline YOB 1930 & 0.210 & 25,029 & 0.209 & 11,494 & 0.201 & 10,103 \\
\hline YOB 1931 & 0.206 & 25,029 & 0.195 & 11,494 & 0.206 & 10,103 \\
\hline YOB 1932 & 0.204 & 25,029 & 0.211 & 11,494 & 0.202 & 10,103 \\
\hline YOB 1933 & 0.189 & 25,029 & 0.190 & 11,494 & 0.196 & 10,103 \\
\hline YOB 1934 & 0.191 & 25,029 & 0.195 & 11,494 & 0.196 & 10,103 \\
\hline \multicolumn{7}{|l|}{ SOCIO-ECONOMIC STATUS. } \\
\hline Wedlock & 0.893 & 25,029 & 0.939 & 11,494 & 0.907 & 10,103 \\
\hline SES Professional/Technical & 0.046 & 25,029 & 0.041 & 11,494 & 0.047 & 10,103 \\
\hline SES Administrative/Managerial & 0.022 & 25,029 & 0.017 & 11,494 & 0.024 & 10,103 \\
\hline SES Clerical & 0.019 & 25,029 & 0.011 & 11,494 & 0.013 & 10,103 \\
\hline SES Sales & 0.030 & 25,029 & 0.023 & 11,494 & 0.023 & 10,103 \\
\hline SES Service & 0.017 & 25,029 & 0.014 & 11,494 & 0.010 & 10,103 \\
\hline SES Agricultural & 0.319 & 25,029 & 0.390 & 11,494 & 0.432 & 10,103 \\
\hline SES Production & 0.432 & 25,029 & 0.410 & 11,494 & 0.346 & 10,103 \\
\hline SES Unknown & 0.115 & 25,029 & 0.092 & 11,494 & 0.105 & 10,103 \\
\hline Crisis area & 0.045 & 25,029 & 0.071 & 11,494 & -0.014 & 10,103 \\
\hline \multicolumn{7}{|l|}{ ELIGIBILITY \& UTILISATION. } \\
\hline Treated Parish & 0.510 & 24,374 & 0.523 & 11,406 & 0.472 & 9,793 \\
\hline Duration of Eligibility & 4.255 & 24,374 & 4.266 & 11,406 & 4.203 & 9,793 \\
\hline Enrolment & - & - & - & - & 0.122 & 9,793 \\
\hline Utilisation & - & - & - & - & 0.523 & 9,793 \\
\hline \multicolumn{7}{|l|}{ CONTEXTUAL VARIABLES. } \\
\hline Institutional Delivery & 0.345 & 24,374 & 0.263 & 11,406 & 0.263 & 9,793 \\
\hline Weeks Compulsory Schooling & 228.947 & 24,374 & 229.434 & 11,406 & 226.745 & 9,793 \\
\hline Seven Years Compulsory & 0.781 & 24,374 & 0.781 & 11,406 & 0.580 & 9,793 \\
\hline Secondary Enrolment & 0.223 & 22,434 & 0.160 & 10,301 & 0.184 & 9,109 \\
\hline
\end{tabular}

The columns denoted 'All' contain statistics for the entire sample. The columns denoted 'Mother FE' contain statistics for all births with at least one sibling in the data; this is the sample used in Panels B and $\mathrm{C}$ of Table 1. The columns denoted 'Utilization' contain statistics for the utilization sample consisting of treated parishes for which utilization data were available, and their matched controls. This is the sample used in utilization regressions (Table 6) and in 2SLS estimates (Table 7). Variable definitions and sources are provided in Appendix A 
Table C.15. Ineligible Children Born Before the Intervention With and Without Younger Siblings.

\begin{tabular}{lccccc}
\hline \multirow{2}{*}{ Variable } & \multicolumn{2}{c}{ Treated } & & \multicolumn{2}{c}{ Control } \\
\cline { 2 - 3 } \cline { 5 - 6 } & S11 & S10 & & S01 & S00 \\
\hline Birthdate & 1930.377 & 1930.357 & & 1930.386 & 1930.382 \\
Maternal Age & 28.866 & 29.005 & & 28.924 & 28.270 \\
Wedlock & 0.936 & 0.929 & & 0.928 & 0.916 \\
Maternal IMR & 0.001 & 0.001 & & -0.001 & 0.003 \\
SES High & 0.071 & 0.085 & & 0.092 & 0.077 \\
SES Low & 0.159 & 0.136 & & 0.158 & 0.155 \\
\hline
\end{tabular}

The table show observable characteristics of children born before the intervention who were matched according to the protocol described on page 28, $S 11$ denotes children who were born before the intervention in a treated region, who had an eligible younger sibling. $S 10$ denotes children who were born before the intervention in a treated region who did not have an eligible younger sibling. $S 01$ denotes a child born in a control region with a younger sibling born in the intervention period, and $S 00$ denotes a child born in a control region without a younger sibling born during the intervention period. 
D Appendix Figures 


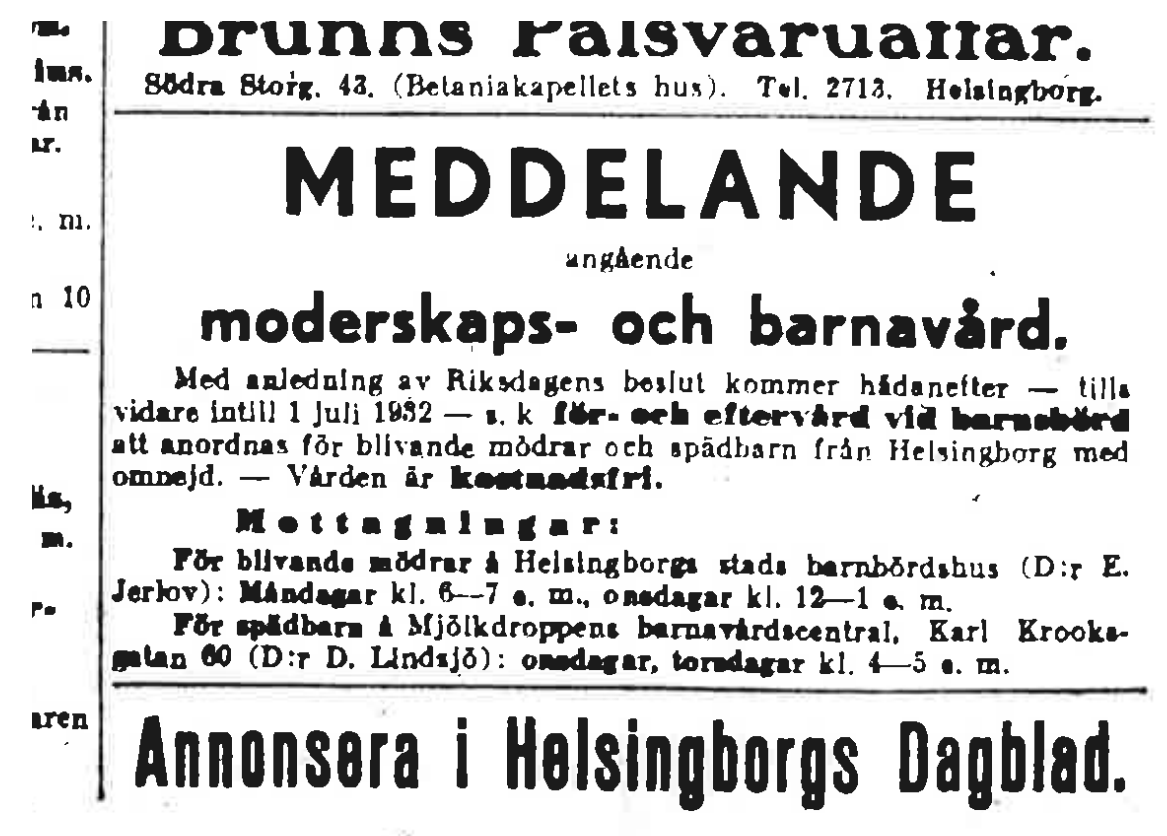

Figure D.9. Advertisment from Daily Helsingborgs Dagblad (1931), Announcing the Services and Opening Hours of the Centre. 

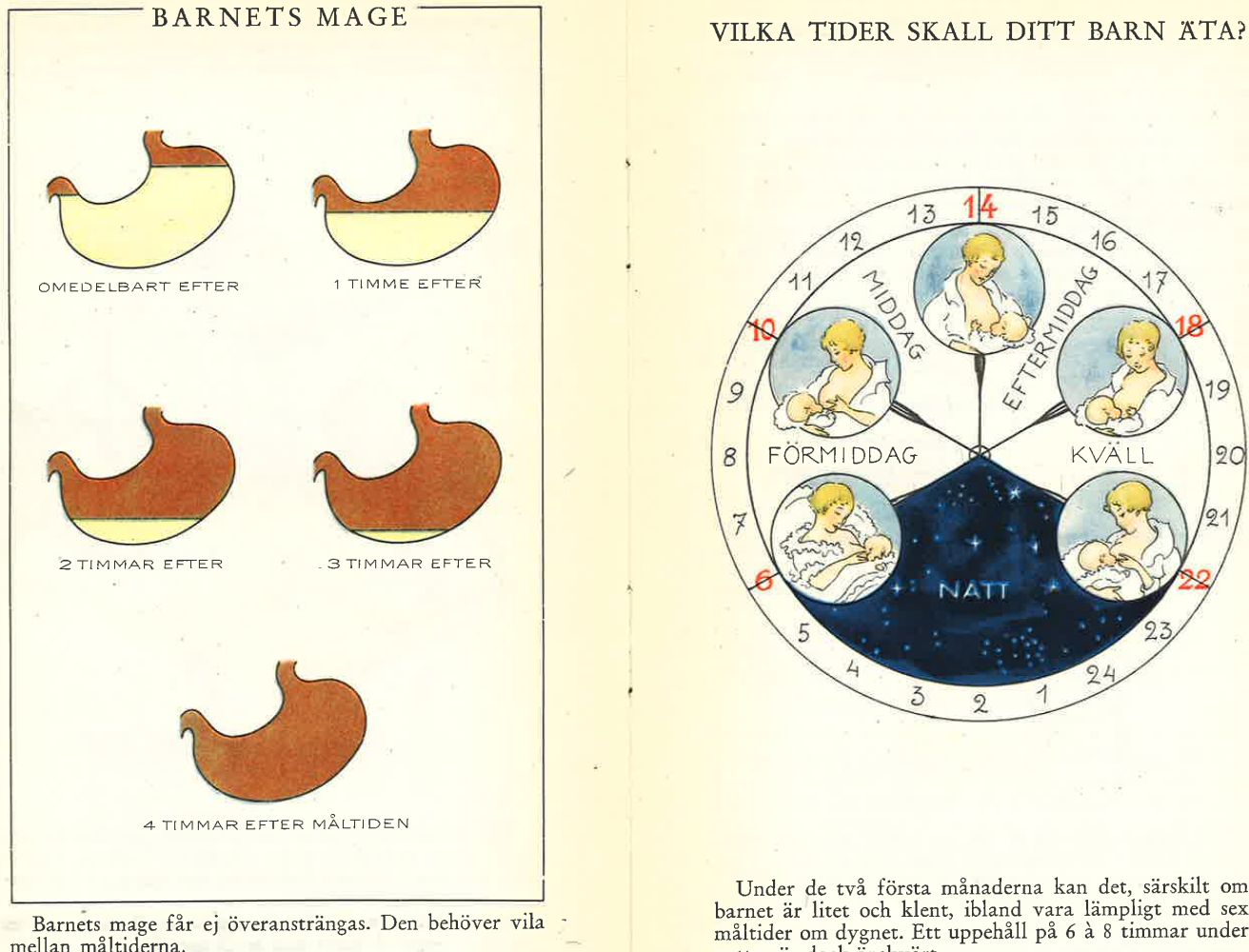

Under de två första månaderna kan det, särskilt om Under de tva forsta mandent kän baltider mellan måltiderna. natten är dock önskvärt.

Figure D.10. Advice on appropriate feeding of infants from leaflet provided within the Infant Care Intervention. The left panel shows how the stomach of the infant empties in the 4 hours following a feed and the right panel suggests intervals for breastfeeding. 


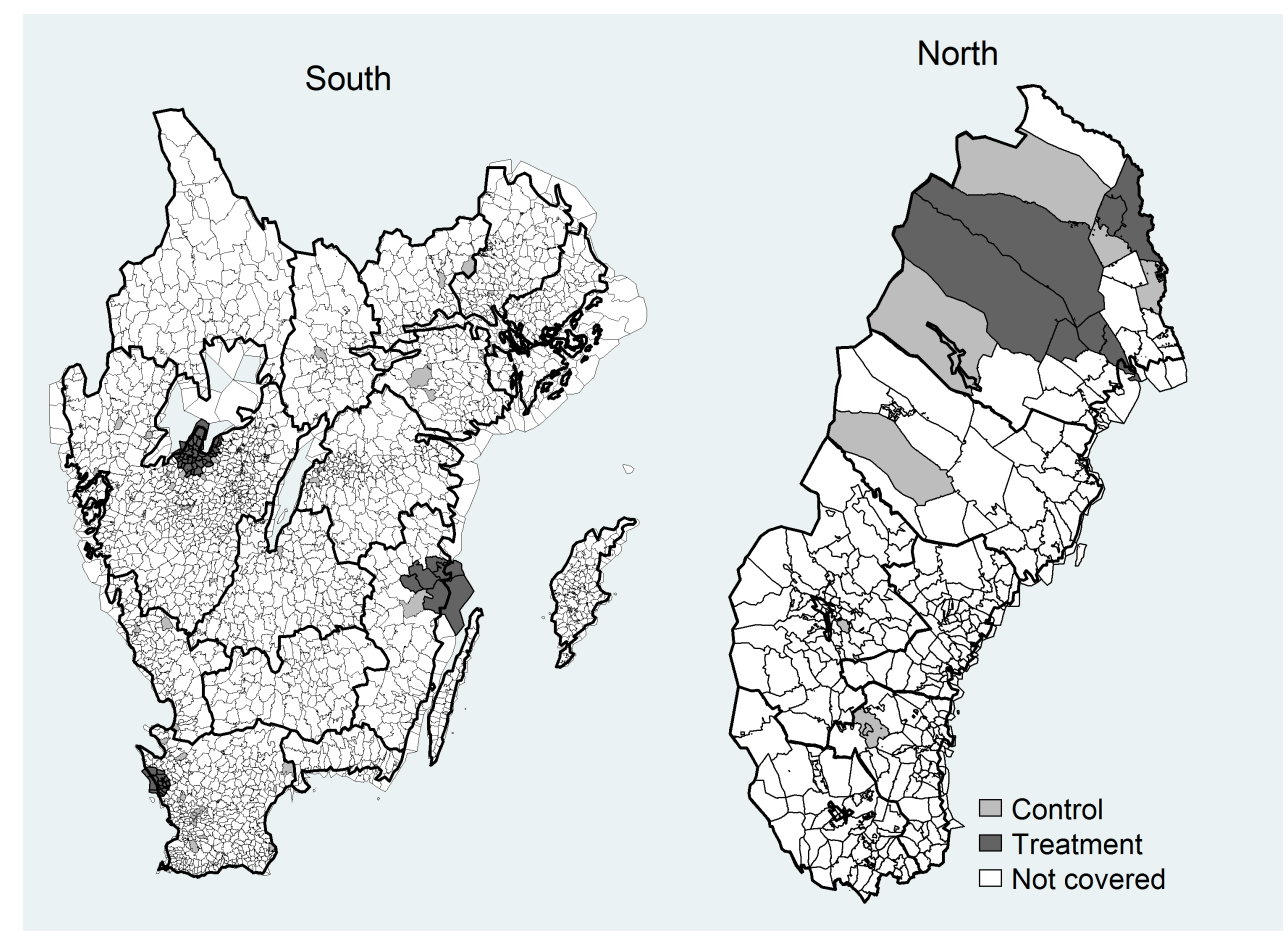

Figure D.11. Municipalities Containing Treated and Control Districts. 